\title{
Effects of Soil-Structure Interaction on Torsionally Coupled Base Isolated Machine Foundation under Earthquake Load
}

\author{
Karmegam Rajkumar, Ramanathan Ayothiraman (D), and Vasant A. Matsagar (iD \\ Department of Civil Engineering, Indian Institute of Technology (IIT) Delhi, Hauz Khas, New Delhi 110 016, India \\ Correspondence should be addressed to Ramanathan Ayothiraman; araman@civil.iitd.ac.in
}

Received 26 December 2020; Revised 9 April 2021; Accepted 7 May 2021; Published 20 May 2021

Academic Editor: Grzegorz Zywica

Copyright ( 2021 Karmegam Rajkumar et al. This is an open access article distributed under the Creative Commons Attribution License, which permits unrestricted use, distribution, and reproduction in any medium, provided the original work is properly cited.

\begin{abstract}
In this paper, the influence of soil-structure interaction (SSI) on a torsionally coupled turbo-generator (TG) machine foundation is studied under earthquake ground motions. The beneficial effects of base isolators in the TG foundation under earthquake ground motions are also studied duly, considering the effects of SSI. A typical TG foundation is analyzed using a three-dimensional finite element (FE) model. Two superstructure eccentricity ratios are considered to represent the torsional coupling. Soft soil properties are considered to study the effects of SSI. This research concludes that the effects of torsional coupling alter the natural frequencies, if ignored, could lead to unsafe design. The deck accelerations and displacements are increased with an increase in superstructure eccentricity. On the other hand, the deck accelerations and displacements are greatly reduced with the help of base isolators, thus confirming the beneficial use of base isolators in machine foundations to protect the sensitive equipment from the strong earthquake ground motions. However, the effects of SSI reduce the natural frequencies of the TG foundation resting on soft soil conditions and activate the higher mode participation, resulting in amplifying the response.
\end{abstract}

\section{Introduction}

Machine foundations are used to help in the distribution of the machine loads and mitigate the vibrations developed due to the rotating machine parts. Turbo-generator foundations also known as framed-type machine foundations are the common supporting system for rotary machines of medium to high-speed $[1,2]$. In general, the permissible displacement amplitude of vibration for the TG foundations supporting rotary machine is very low, i.e., typically in the range of 10-50 microns, depending on the operating speed, type, and function of the machine [3]. If underdesigned, it may affect the functioning of sensitive machines, formation of cracks in concrete elements, excessive wearing in bearings, etc. Such harmful effects are significant in TG foundations and need to be designed adequately for the dynamic loads to control the excessive vibration and avoid possible failures.

1.1. Studies on Effects of SSI in Machine Foundation. The effects of SSI on block type machine foundation are well established using simplified models due to its predictable modes of vibration such as vertical, horizontal, and rocking modes $[4,5]$. However, there are limited studies available on the adverse effects of SSI on TG foundations. Few of such studies in the recent past are discussed here. Dynamic analysis and design of TG foundations located in high seismic regions are studied by few researchers [6-8] using FE model and concluded that the site conditions play an important role in dynamic requirements. Recently few researchers [9-11] conducted the dynamic analysis of machine foundations under machine induced vibration considering different soil modeling approaches in FE model and concluded that the structural response to dynamic loads is greatly influenced by the soil medium.

Currently, either simplified methods without considering the effects of soil or rigorous finite element method (FEM) considering detailed soil-structure interaction (SSI) are being adopted for TG foundation in practice. From the above studies, it is evident that ignoring the effects of the SSI may lead to the unsafe design of the machine foundations, 
especially under earthquake forces. Therefore, it will be interesting to study the dynamic response of TG foundation under different earthquake ground motions while duly considering the effects of SSI, which is attempted in this work.

1.2. Studies on Base Isolation Techniques in Machine Foundation. For protecting structures from the damaging effects of vibrations, base isolation is considered one of the most ingenious ways. Base-isolated structures are found effective in mitigating the damaging consequences of earthquake excitation by decoupling the structure from the ground motions [12-16]. The behavior of base isolation systems and the base-isolated structures has been well established, and various codes of practice are available in different countries [17, 18]. Very few researchers have implemented the base isolation techniques in machine foundation and found them quite effective in controlling seismic response. Su et al. [19] used resilient-friction based isolator (RFBI) in structures to mitigate vibrations due to machines. They concluded that the RFBI helped in reducing the seismic response of the rotating components to potentially damaging ground excitations. Ivovich and Savovich [20] had proposed a novel approach for isolation of floor machines by using a lever-type inertial vibration corrector, which reduces transmission of excitations from machines to the foundation. Closed-form analytical solutions were developed by Chehab and Naggar [21] for mounting systems (base isolation) in foundations supporting hammers/presses. A comprehensive review of advances made in nonlinear passive vibration isolators has been made by Ibrahim [22]. The author [22] presented state-of-the-art pertaining also to the isolation of machine vibrations through different passive techniques.

In this study, an attempt is made by implementing elastomeric type isolators in TG foundation and time-history analysis is carried out for different earthquake ground motions to quantify the effects of SSI on base-isolated machine foundation.

\subsection{Studies on Effects of Torsional Coupling and SSI on Base-} Isolated Structures. Observations of damages on structures in the recent past have shown the importance of torsional vibrations induced by earthquake ground motions. The eccentricity between the center of mass (CM) and the center of stiffness (CS) may lead to torsional coupling in framed structures. Though CM and CS coincide in the symmetrical buildings, it has been observed that there exists some uncertainty, and it is always safe to design the structures considering some degree of accidental torsion. Most of the codes prescribed the need to include 5-10\% accidental torsion by assuming eccentricity in different directions in the framed structure while analyzing it [23]. In the past few decades, several research works have been reported on the effects of torsional coupling in nonisolated structures [24-27] and base-isolated structures [28-30]. Also, the effects of SSI on base-isolated structures were also studied by many researchers [31-33]. From these studies, it is inferred that the torsional response was found to be substantial even for small eccentricity and the combination of translational and torsional effects significantly increased the lateral displacement of vertical members located at the edge. Interestingly, asymmetries are quite common in TG foundations due to the presence of multiple openings and uneven distribution of machine/equipment masses on deck slab. This would lead to the prevalence of torsional coupling in most TG foundations where permissible limits are stringent. In addition, the effects of SSI also modify the dynamic response of base-isolated structures. Therefore, it will be interesting to study the dynamic behavior of TG foundation under the influence of torsional coupling while duly considering the effects of SSI. In addition, the beneficial effects of base isolators in TG foundation under different earthquake ground motions are also studied.

\section{Finite Element Modeling}

Dynamic analysis of the TG foundation is carried out in a finite element (FE) software ABAQUS 6.11. A schematic diagram of base-isolated machine foundation resting on soil medium is shown in Figure 1. For the present study, a typical TG foundation of following structural dimensions is used: (i) deck slab: $18.2 \mathrm{~m}$ (length) $\times 9.0 \mathrm{~m}$ (width) $\times 1.4 \mathrm{~m}$ (thick); (ii) base raft: $19.0 \mathrm{~m}$ (length) $\times 10.0 \mathrm{~m}$ (width) $\times 0.8 \mathrm{~m}$ (thick); (iii) raft foundation: $19.0 \mathrm{~m}$ (length) $\times 10.0 \mathrm{~m}$ (width) $\times 1.2 \mathrm{~m}$ (thick); and (iv) height and cross-sections of the columns considered are $10.0 \mathrm{~m}$ and $1.2 \mathrm{~m} \times 1.2 \mathrm{~m}$, respectively.

The present study investigates the effects of elastomeric type isolators on machine foundation against earthquake ground motion. The lead-rubber bearing (LRB) is the commonly used elastomeric type isolator. The LRB consists of rubber and thin steel plates in alternate layers, which are mounted at the top and bottom mounting plates as shown in Figure 2(a). This isolator can isolate earthquakes by providing flexibility in the horizontal direction and the lead core provides an additional means of energy dissipation. High vertical stiffness to carry loads to foundation is achieved by the steel plates. The idealized model of the LRB is shown in Figure 2(b). The LRB is characterized by the time period $\left(T_{b}\right)$, damping of isolation system $\left(\xi_{b}\right)$, and normalized yield strength $\left(F_{0}\right)$ [30]. The three-dimensional FE model of the base-isolated TG foundation used in the present study is shown in Figure 3. The modeling assumptions considered are described subsequently.

2.1. Modelling of Materials. The selection of proper constitutive models to define material behavior is essential in numerical analysis. The RC frame is assumed to remain within the elastic limit during the transient vibration response under earthquake excitation and hence the material properties considered are Young's modulus of concrete, $E_{\mathrm{s}}=30 \mathrm{GPa}$; mass density, $\rho_{\mathrm{c}}=2500 \mathrm{~kg} / \mathrm{m}^{3}$; Poisson's ratio, $\mu_{\mathrm{c}}=0.15$. Most of the past research on soil-structure interaction had used elastic material models to simulate the soil behavior. In this study, the elastic material model is used to simulate the soil behavior. The soil properties considered 


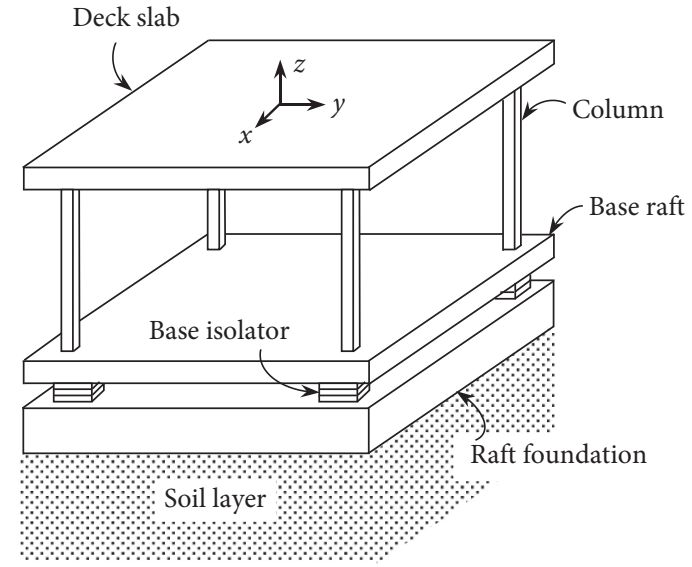

(a)

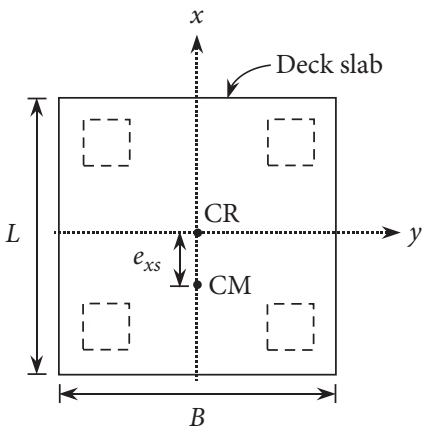

(b)

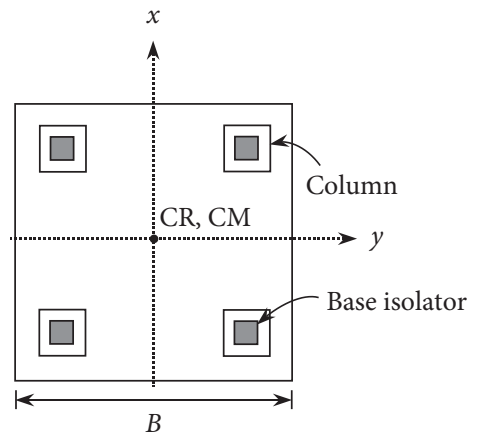

(c)

Figure 1: Schematic diagram of base-isolated machine foundation; (a) three-dimensional view, (b) plan view at deck level, and (c) plan view at base raft level.

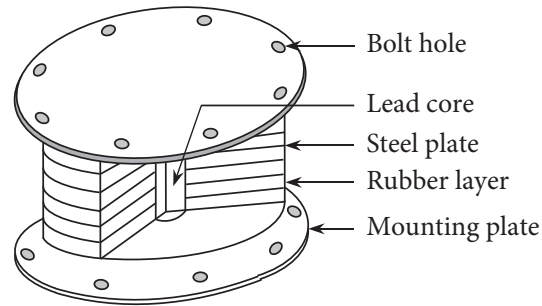

(a)

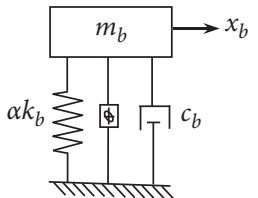

(b)

FIgURE 2: Schematic representation of lead rubber bearing (LRB); (a) actual model and (d) idealized

are shear wave velocity, $v_{s}=150 \mathrm{~m} / \mathrm{s}$; mass density, $\rho_{\mathrm{s}}=1600 \mathrm{~kg} / \mathrm{m}^{3}$; Poisson's ratio, $\mu_{\mathrm{s}}=0.40[23,34]$. The elastic properties for the base isolator are calculated based on the isolator time period [30]. Following isolator properties are considered in the present study: isolator time period$=2.5 \mathrm{sec} ; \quad$ isolator $\quad$ damping $=5 \%$; yield displacement $=2.5 \mathrm{~cm}$.

The critical damping ratio of the superstructure is taken as $5 \%$. The damping coefficient of $5 \%$ is considered for the base isolator. A constant value of $5 \%$ equivalent damping ratio is used for the foundation-soil system as per the recommendation of ACI 351.3R-04 (2004). Few researchers used this type of damping in dynamic soil-structure interaction analysis $[35,36]$. The damping matrix is $(\mathrm{C})=\beta(\mathrm{K})$, in which $(\mathrm{K})$ is the stiffness matrix and $\beta$ is the damping coefficient $\left(\beta=2 \xi / \omega_{0}\right.$, where $\omega_{0}$ is the predominant frequency of loading and $\xi$ is the material damping ratio which is assumed to be $5 \%$ for foundation-soil system.

2.2. Continuum Elements. Twenty-node cubic solid continuum (C3D20) elements are used for modeling the TG foundation. Eight-node cubic solid continuum (C3D8) elements are used for modeling the soil medium. Connector element is used to model the base isolators. The column is considered as a cantilever beam (shape = square cross section; length $=10 \mathrm{~m}$; width $=0.5 \mathrm{~m}$ ) fixed at the base for the purpose of conducting mesh sensitivity test. A transverse 


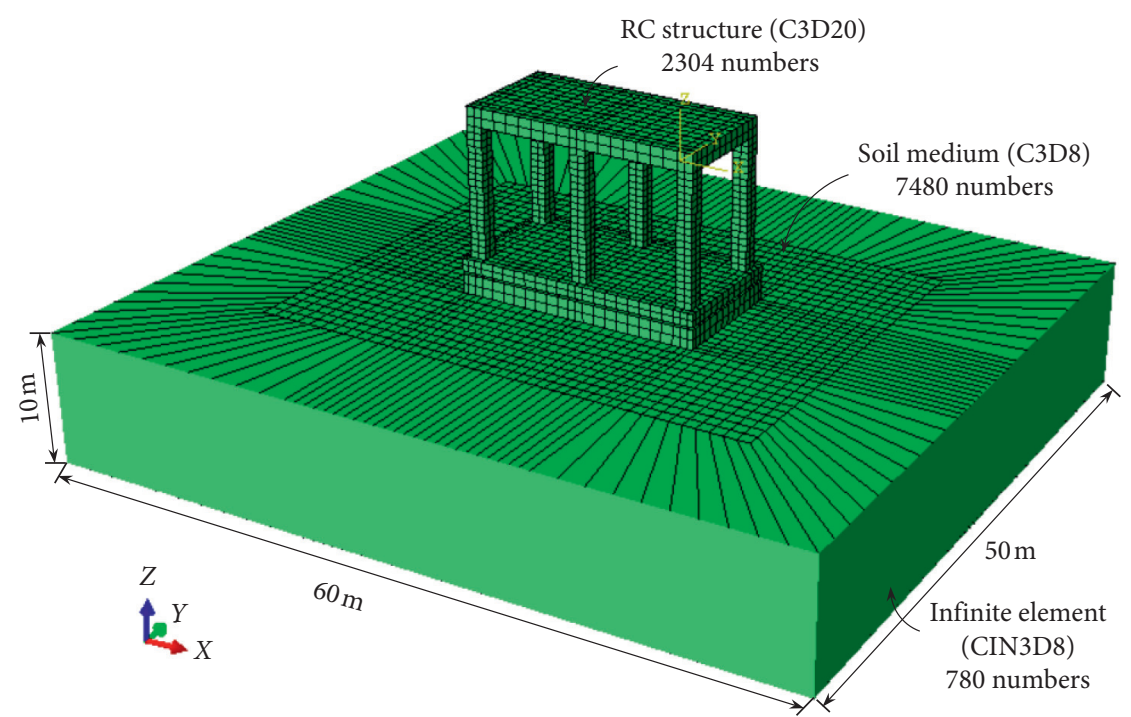

FIgURE 3: Three-dimensional FE model of framed-type machine foundation resting on a soil medium.

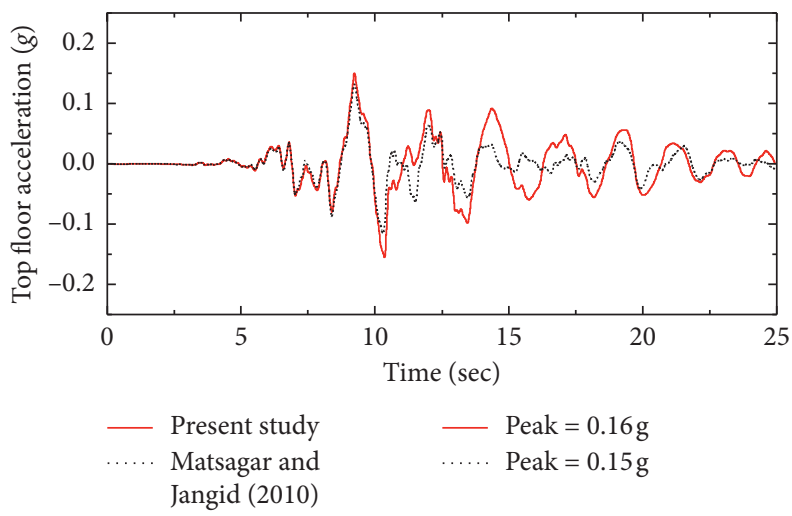

FIGURE 4: Comparison of deck acceleration for base-isolated structures.

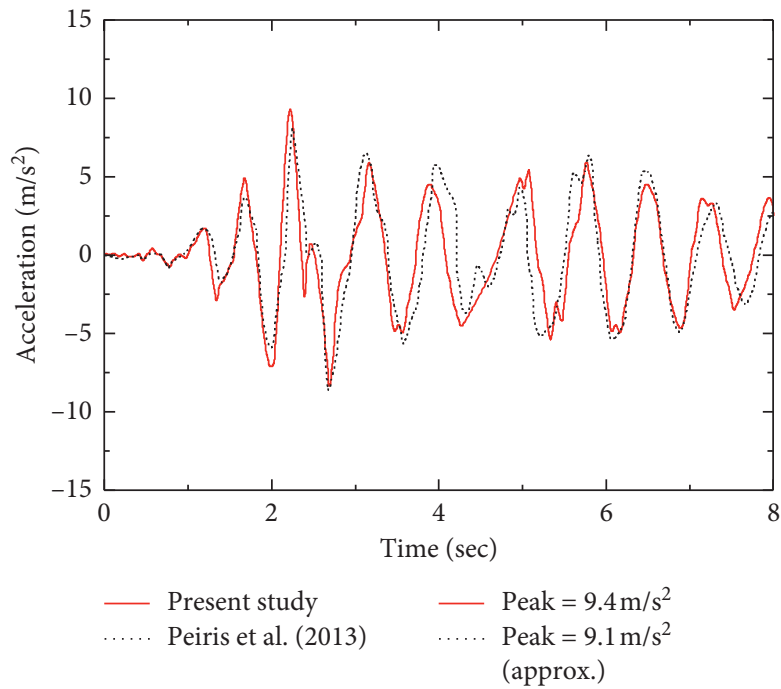

FIgURE 5: Free-field response obtained from the FE analysis 


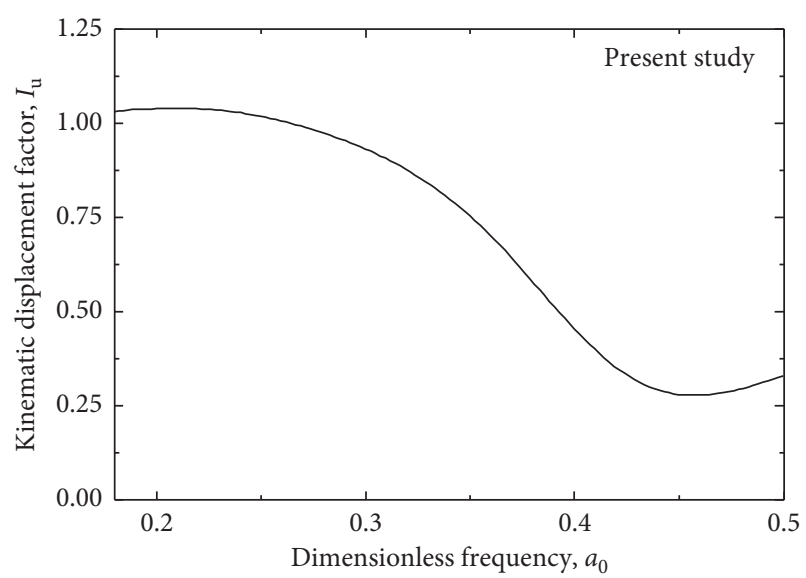

(a)

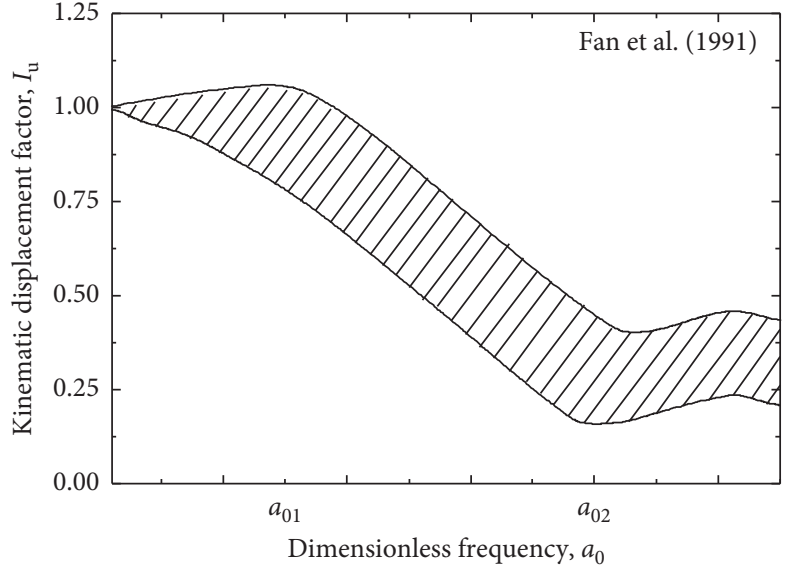

(b)

Figure 6: Pile head response under a base excitation

TAble 1: Natural frequency obtained from the FE analysis.

\begin{tabular}{lccccccc}
\hline \multirow{2}{*}{ Case } & & \multicolumn{2}{c}{ Natural frequency in lateral mode (Hz) } & \multicolumn{3}{c}{ Natural frequency in torsional mode (Hz) } \\
& & Without SSI & With SSI & \% change & Without SSI & With SSI & \% change \\
\hline \multirow{2}{*}{ Torsionally uncoupled } & & 3.26 & 2.30 & 29.40 & 4.48 & 3.31 \\
\multirow{2}{*}{ Torsionally coupled } & $e_{\mathrm{r}}=0.05$ & 3.11 & 2.21 & 28.91 & 4.32 & 3.35 \\
& $e_{\mathrm{r}}=0.15$ & 2.75 & 2.00 & 27.52 & 4.05 & 3.24 & 19.93 \\
\hline
\end{tabular}

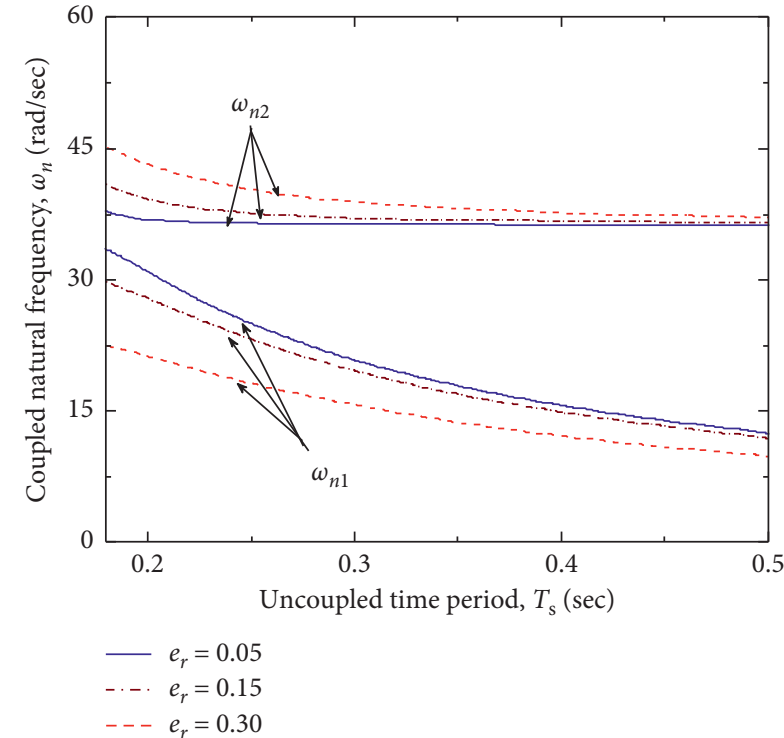

(a)

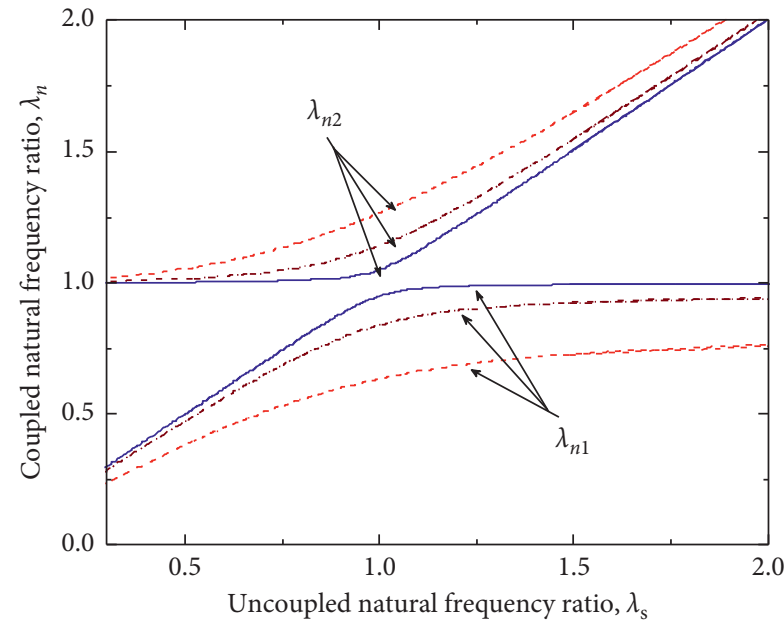

(b)

Figure 7: Effect of torsional coupling on natural frequency.

TABLE 2: Input earthquake ground motions. 
TABLe 3: Peak deck acceleration and displacement obtained from the FE analysis of the nonisolated machine foundation.

\begin{tabular}{|c|c|c|c|c|c|c|c|}
\hline \multirow[t]{2}{*}{ Case } & & \multicolumn{2}{|c|}{$\begin{array}{c}\text { Peak deck acceleration, } \ddot{u}_{y g} \\
(g)\end{array}$} & \multicolumn{2}{|c|}{$\begin{array}{l}\text { Peak deck displacement, } u y \\
(\mathrm{~mm})\end{array}$} & \multicolumn{2}{|c|}{$\begin{array}{l}\text { Peak deck displacement, } u_{x} \\
(\mathrm{~mm})\end{array}$} \\
\hline & & Without SSI & With SSI & Without SSI & With SSI & Without SSI & With SSI \\
\hline \multicolumn{8}{|c|}{ Imperial Valley, array \#5, 1979} \\
\hline Torsionally uncoupled & & 1.19 & 3.31 & 28.26 & 138.54 & 0 & 0 \\
\hline \multirow{2}{*}{ Torsionally coupled } & $e_{\mathrm{r}}=0.05$ & 1.36 & 3.21 & 35.63 & 142.69 & 1.60 & 5.31 \\
\hline & $e_{\mathrm{r}}=0.15$ & 1.63 & 2.80 & 54.06 & 141.92 & 6.15 & 16.25 \\
\hline \multicolumn{8}{|l|}{ Northridge, 1994} \\
\hline Torsionally uncoupled & & 2.39 & 4.84 & 56.35 & 189.12 & 0 & 0 \\
\hline \multirow{2}{*}{ Torsionally coupled } & $e_{\mathrm{r}}=0.05$ & 2.60 & 4.67 & 67.80 & 188.24 & 2.99 & 8.22 \\
\hline & $e_{\mathrm{r}}=0.15$ & 2.73 & 3.99 & 89.03 & 174.78 & 10.58 & 24.67 \\
\hline \multicolumn{8}{|l|}{ Kobe, 1995} \\
\hline Torsionally uncoupled & & 2.04 & 5.41 & 48.58 & 220.71 & 0 & 0 \\
\hline \multirow{2}{*}{ Torsionally coupled } & $e_{\mathrm{r}}=0.05$ & 2.50 & 5.40 & 64.65 & 236.42 & 2.96 & 8.82 \\
\hline & $e_{\mathrm{r}}=0.15$ & 3.25 & 4.32 & 106.30 & 263.25 & 12.47 & 20.75 \\
\hline
\end{tabular}
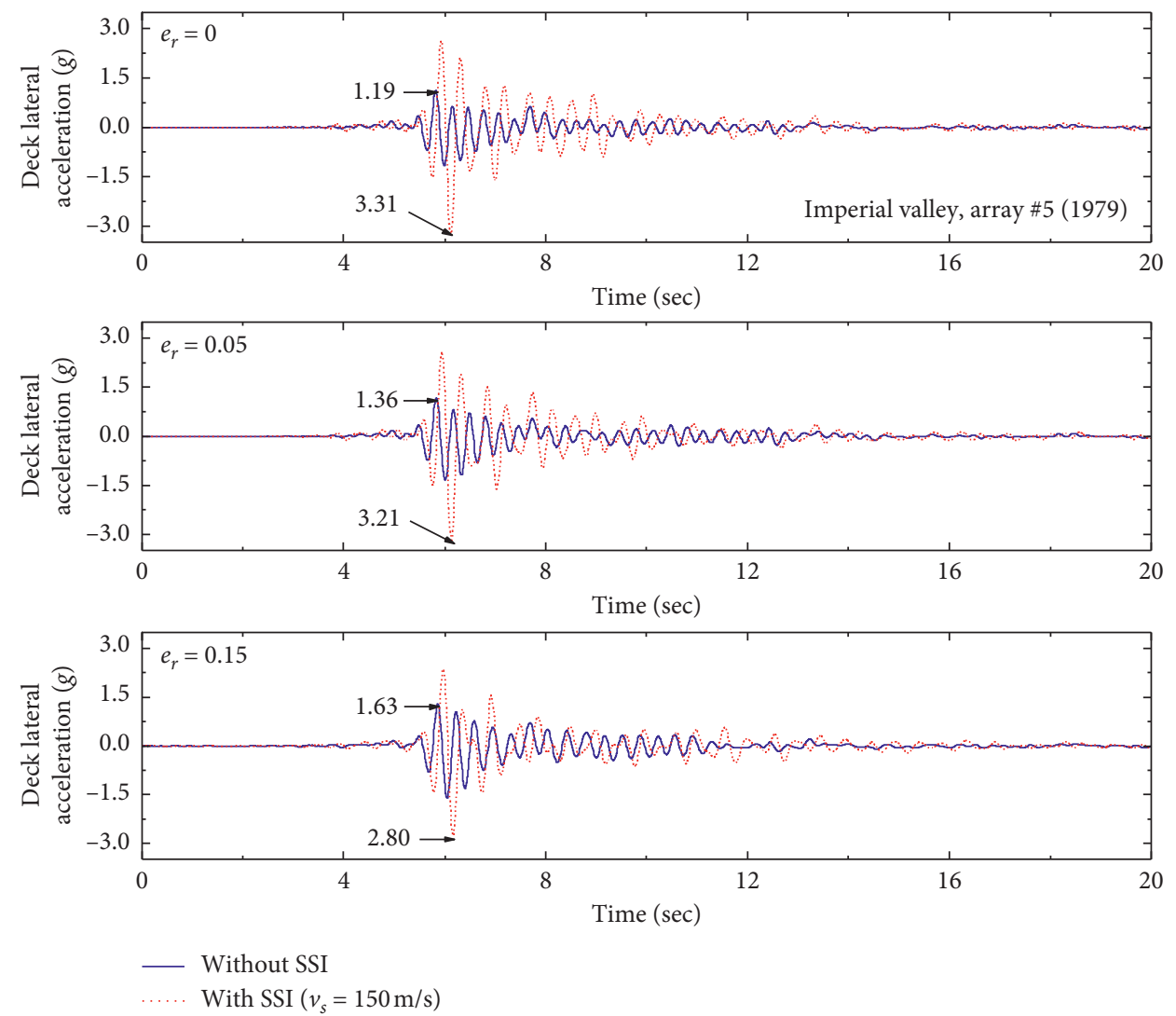

FIGURE 8: Acceleration time-history response of torsionally uncoupled and coupled nonisolated framed-type machine foundation under the Imperial Valley, Array \# 5, 1979 earthquake.

load is applied at the top and transverse deflections are obtained from the FE analysis, and then compared with the theoretical values for different mesh sizes. The mesh size yielding results that match more closely with the theoretical prediction are selected for further analysis.

2.3. Boundary Conditions. In the dynamic analysis of soilstructure interaction, the surrounding soil strata are considered as infinite in the horizontal direction. Therefore, it is important to avoid wave reflection at the vertical boundaries. Kelvin elements (spring-dashpot) are widely used to simulate the boundaries. The solution of the constants of Kelvin elements is developed by Novak and Mitwally [37]. Bentley and Naggar [35] and Maheshwari et al. [36] have successfully used the Kelvin elements in their analysis of pile-soil interaction for single and group of piles. In this study, infinite elements (CIN3D8) are used for the simulation of transmitting boundaries. The behavior of infinite elements is 

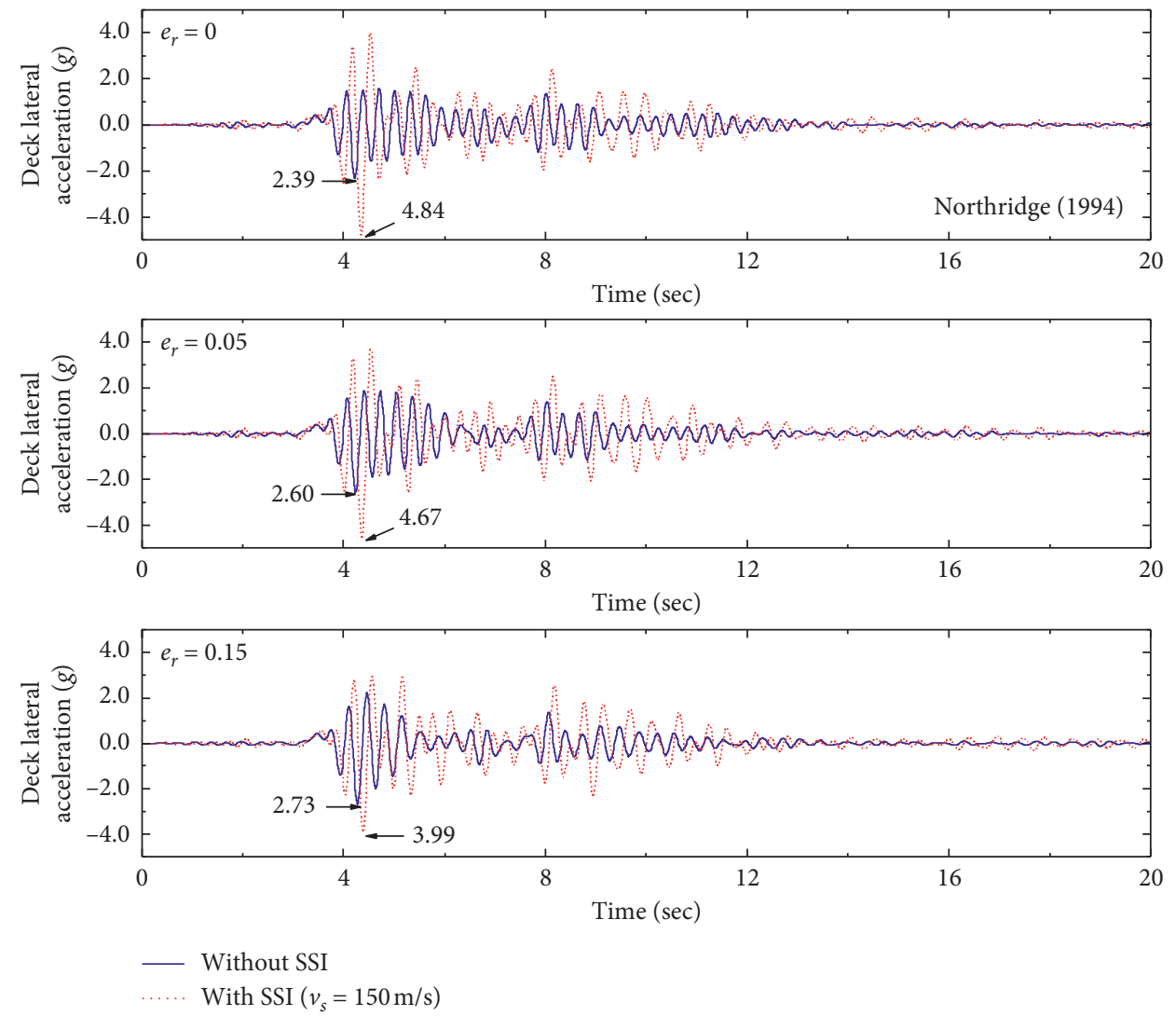

FIGURE 9: Acceleration time-history response of torsionally uncoupled and coupled nonisolated framed-type machine foundation under the Northridge, 1994 earthquake.
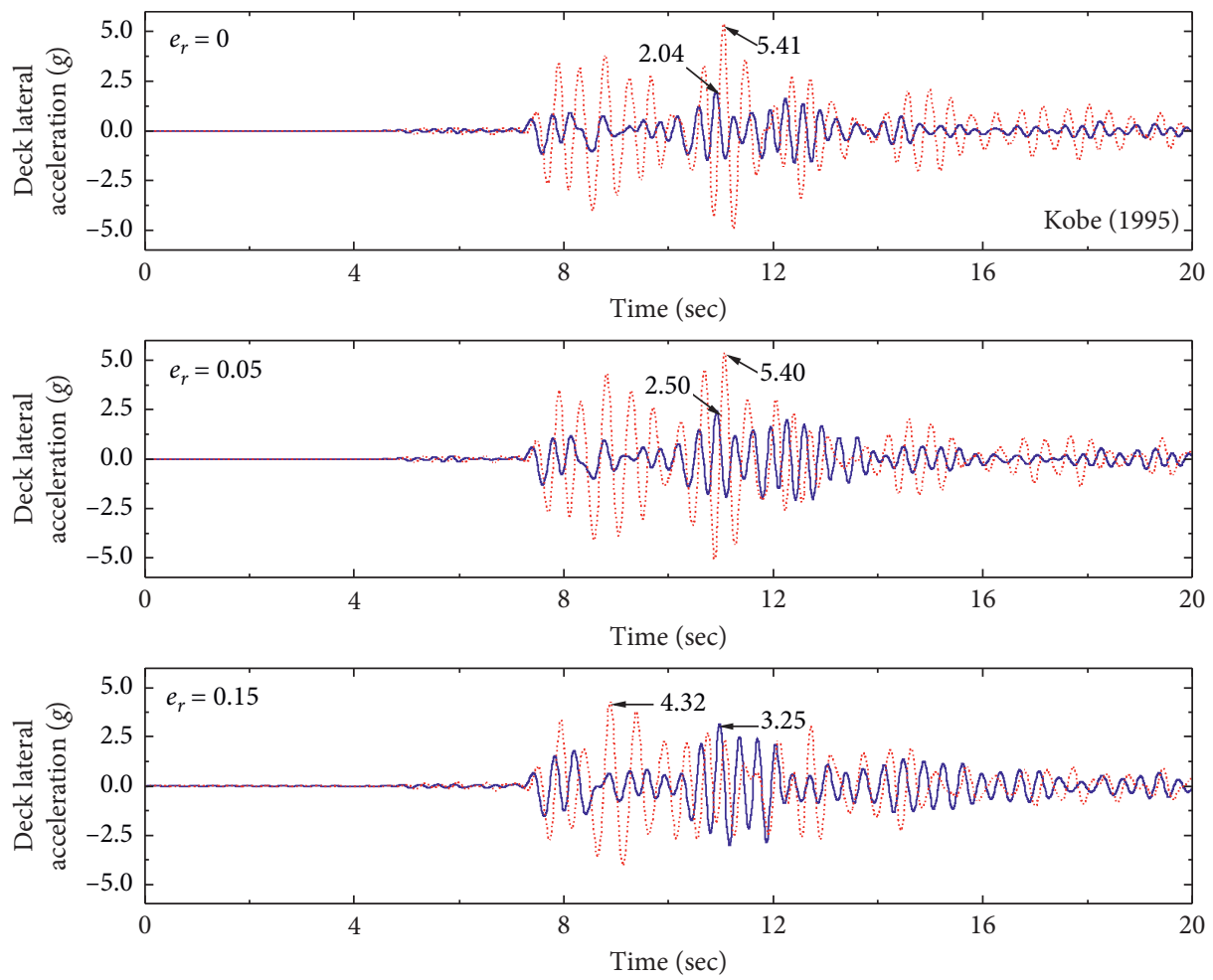

Without SSI

With SSI $\left(v_{s}=150 \mathrm{~m} / \mathrm{s}\right)$

FIGURE 10: Acceleration time-history response of torsionally uncoupled and coupled nonisolated framed-type machine foundation under the Kobe, 1995 earthquake. 

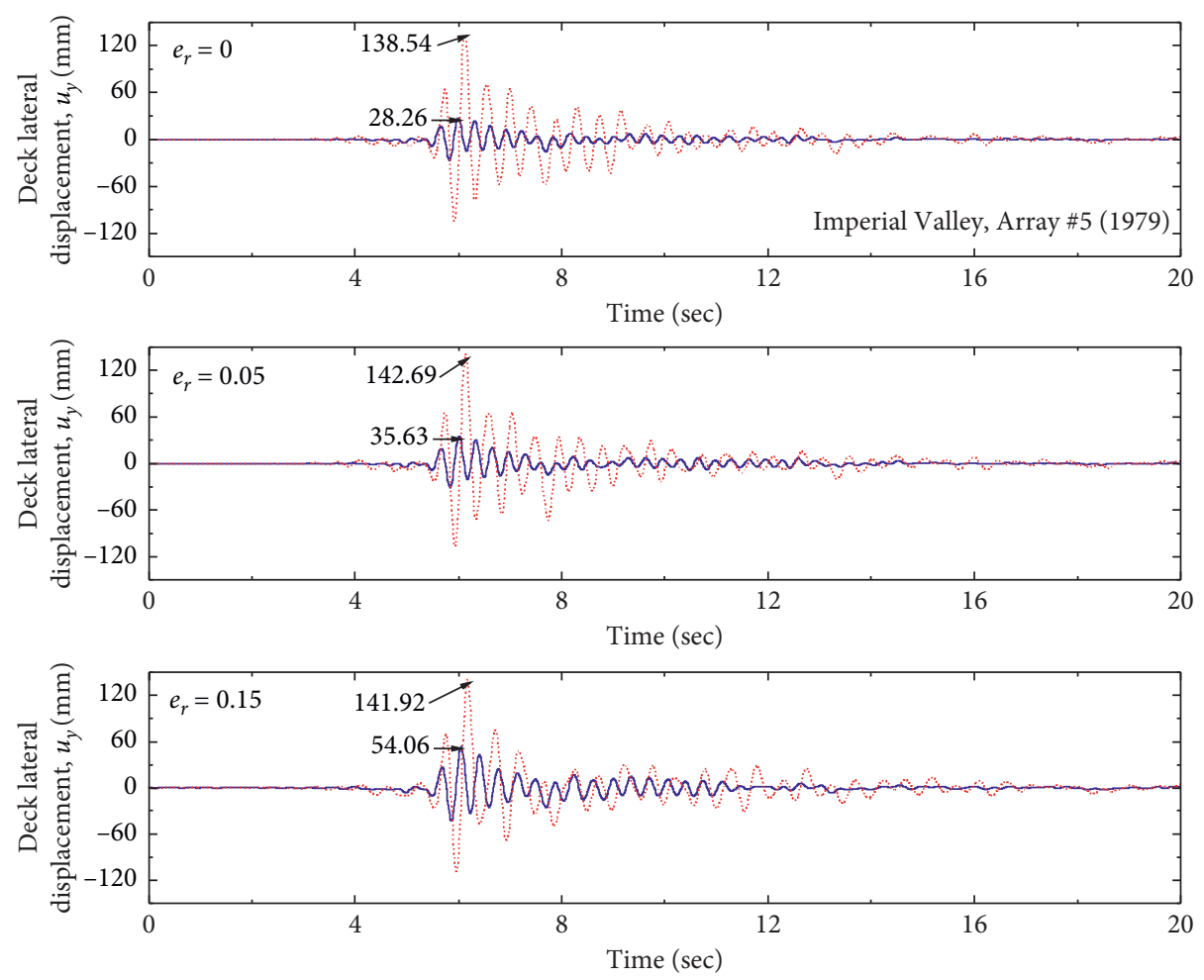

W... With SSI $\left(v_{s}=150 \mathrm{~m} / \mathrm{s}\right)$

FIGURE 11: Displacement time-history response of torsionally uncoupled and coupled nonisolated framed-type machine foundation under the Imperial Valley, Array \# 5, 1979 earthquake.
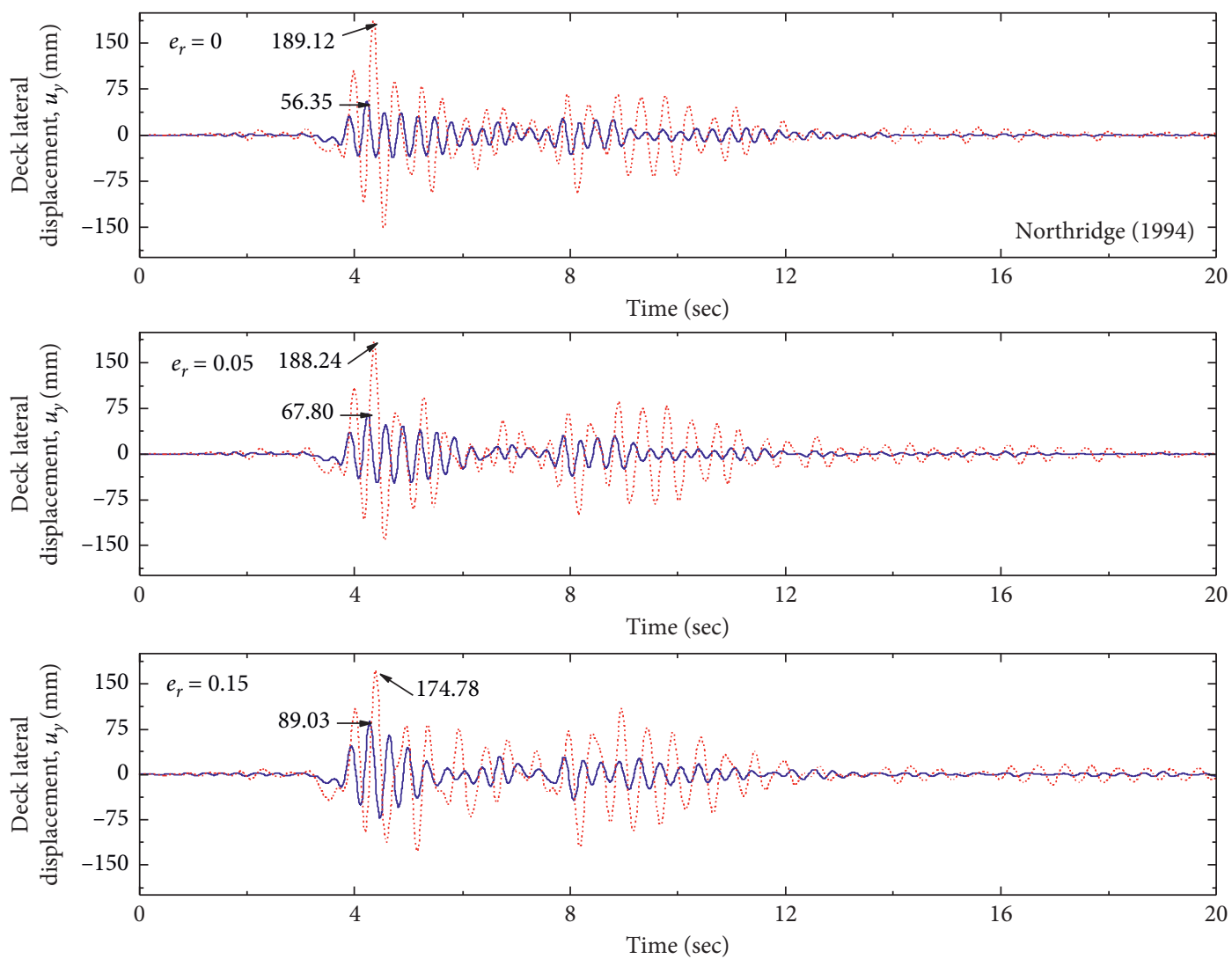

Without SSI
With SSI $\left(v_{s}=150 \mathrm{~m} / \mathrm{s}\right)$

FIGURE 12: Displacement time-history response of torsionally uncoupled and coupled nonisolated framed-type machine foundation under the Northridge, 1994 earthquake 

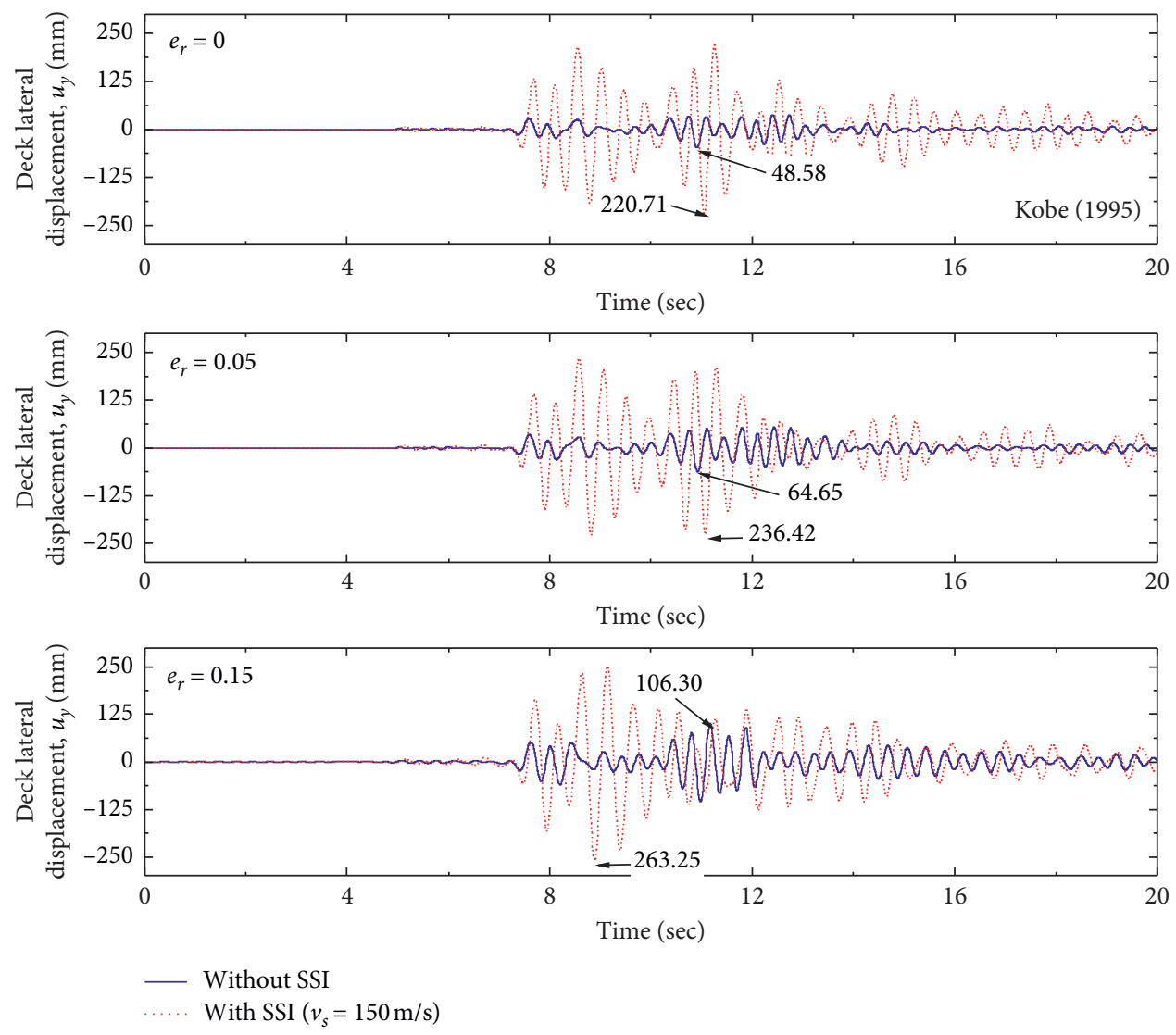

FIGURE 13: Displacement time-history response of torsionally uncoupled and coupled nonisolated framed-type machine foundation under the Kobe, 1995 earthquake.

similar to the behavior of the Kelvin elements, but far end nodes are not allowed to move. During static analysis, infinite elements provide stiffness at the FE model boundaries based on the model of Zienkiewicz et al. [38]. During dynamic analysis, infinite elements provide "quiet" boundaries based on the model of Lysmer and Kuhlemeyer [39]. Zhao and Valliappan [40] had successfully utilized infinite element boundaries in dynamic problems of wave propagation and soil-structure interaction analysis.

2.4. Loading Steps. In soil-structure interaction analysis, it is important to simulate the in-situ conditions before applying any dynamic loads in the model. In this model, loading is applied in two consecutive steps: geostatic step and dynamic loading step. In the geostatic step, the geostatic stress condition is simulated by applying gravity load to the system and a predefined stress field applied to the soil mesh. Then the program creates a force equilibrium system where the insitu stresses are calculated. They are in equilibrium with the external forces under the prescribed boundary conditions and produce negligible deformations. Then the dynamic analysis of the TG foundation is performed in two steps, i.e., free-vibration analysis and forced-vibration analysis. In the free-vibration analysis, the natural frequencies and the mode shapes are extracted from the FE analysis. In the second step, the machine foundation is analyzed under various earthquake ground motions.

\section{Validation of the FE Model}

To ensure the validity of the FE model, the following validation studies are conducted.

3.1. Base-Isolated Structure under Earthquake Loading. The dynamic analysis of base-isolated single-story shear frame is carried out using FE software and the results are compared with the standard literature [14]. The input parameters used for the validation are: Structural time period $=0.25 \mathrm{~s} ; \quad$ structural damping $=5 \%$; isolator time period $=2.5 \mathrm{sec} ; \quad$ isolator damping $=5 \%$; yield displacement $=2.5 \mathrm{~cm}$. Figure 4 shows the results obtained from the FE analysis and reported in standard literature under Imperial Valley, 1979 (Array \# 5) earthquake ground motion. From the figure, it is observed that the time-history response is in close agreement. 

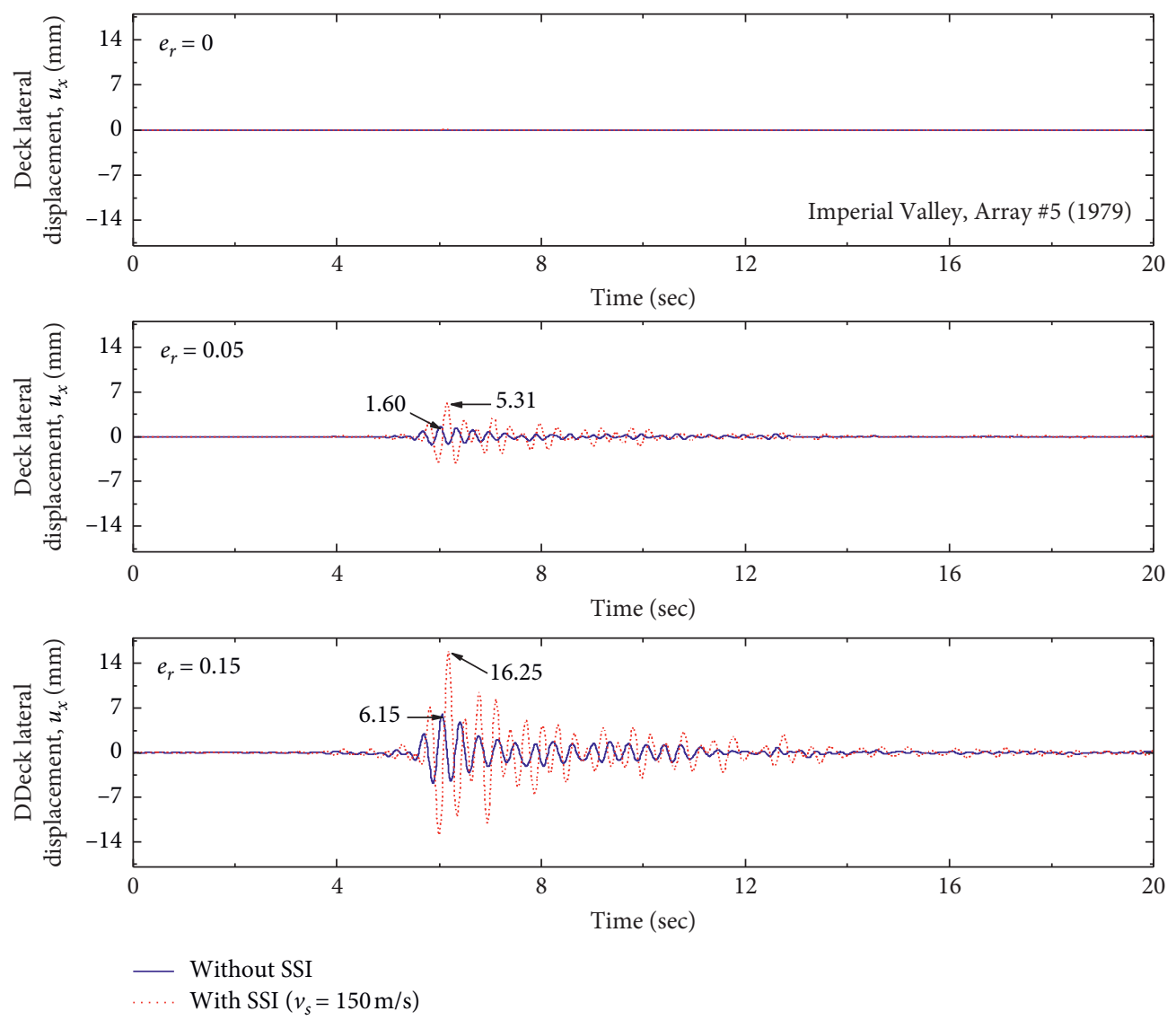

FIGURE 14: Displacement time-history response of torsionally uncoupled and coupled nonisolated framed-type machine foundation under the Imperial Valley, Array \# 5, 1979 earthquake.

3.2. Soil-Structure Interaction under Earthquake Loading. In order to verify the boundary conditions and soil-structure interaction under dynamic loads, FE analysis has been carried out in two conditions: (i) for predicting the free-field motion of a ground considering the data reported in the literature [41] and (ii) for predicting the soil-pile response when subjected to base excitation (as per data of Fan et al. [42]). Validation of the free-field motion is carried out only for the soil profile in the absence of the pile. Here, an excitation is given as a displacement-time history to the base of the profile in order to simulate the seismic waves. The displacement-time history used here is from seismic data for Imperial Valley, 1979 (Array \# 5) earthquake ground motion. Free-field response for the same soil profile and base excitation is obtained (Figure 5) and compared with the results predicted by Peiris et al. [41]. From the figure, it is observed that the free-field responses are in close agreement.

Now, the validation has been carried out for the soil-pile system. In this case, the base of the soil-pile system has been given a horizontal sinusoidal excitation as studied by Fan et al. [42]. For the comparison of results, two factors are defined, namely, kinematic displacement factor, $I_{\mathrm{u}}\left(=\left|\mathbf{U}_{\mathrm{p}}\right| /\right.$ $\mathbf{U}_{\mathrm{ff}}$, where $U_{\mathrm{p}}$ is pile response at top, and $U_{\mathrm{ff}}$ is the amplitude of free-field motion) and dimensionless frequency $a_{0}\left(=\omega_{\mathrm{m}}\right.$ $a / v_{s}$, where $\omega_{\mathrm{m}}$ is the operating frequency, $a$ is pile diameter in this case, $v_{s}$ is the shear wave velocity of soil). Figure 6 shows the results of the present study and the idealized general shape proposed by Fan et al. [42]. As per Fan et al. [42], $I_{u}$ is close to the value of 1 for the low frequency region (i.e., $\left.0<a_{0}<a_{01}\right)$. However, when $a_{0}$ reaches a factor, $a_{01}$ $(\approx 0.2-0.3), I_{u}$ declines rapidly and then fluctuates around a value of about 0.4 after the factor, $a_{02}(\approx 5$ to 10 times the natural frequency of the soil deposit for homogeneous soil profile). From Figure 6, it is evident that the proposed modeling assumption agrees well with the study done by Fan et al.

\section{Numerical Study}

The response quantities considered in the present study are the natural frequency $\left(\omega_{n}\right)$, peak displacement (lateral and torsional), and absolute acceleration at deck level. These response quantities are of importance because the natural frequencies are the key parameter to choose the structural arrangements of a suitable machine foundation. Acceleration and displacement at deck level are the direct measures to check the limiting amplitude of vibration in the machine foundation. And also, the deck acceleration developed in the superstructure is proportional to the force exerted due to earthquake ground motion. For efficient operation of the 

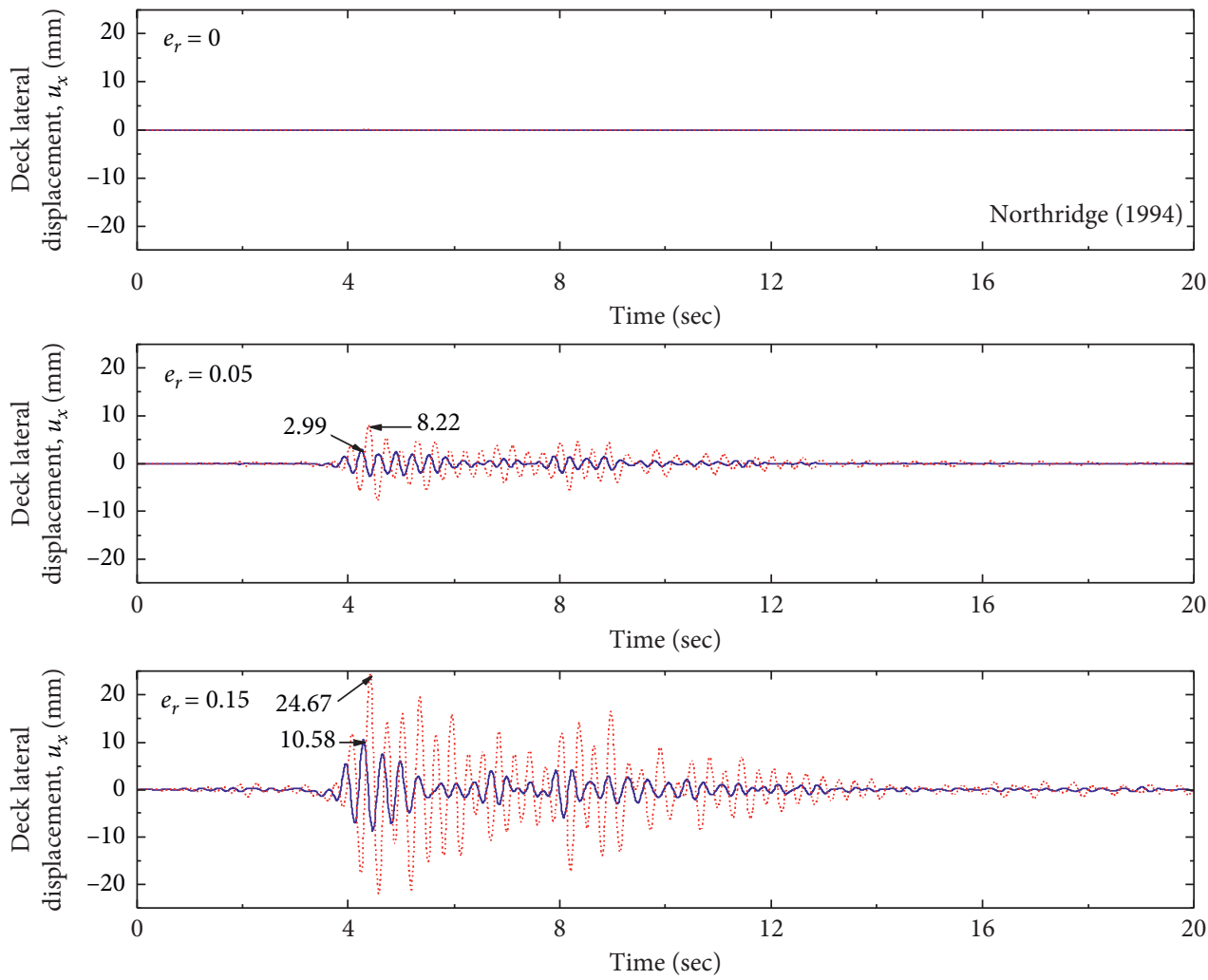

— Without SSI

With SSI $\left(v_{s}=150 \mathrm{~m} / \mathrm{s}\right)$

FIGURE 15: Displacement time-history response of torsionally uncoupled and coupled nonisolated framed-type machine foundation under the Northridge, 1994 earthquake.
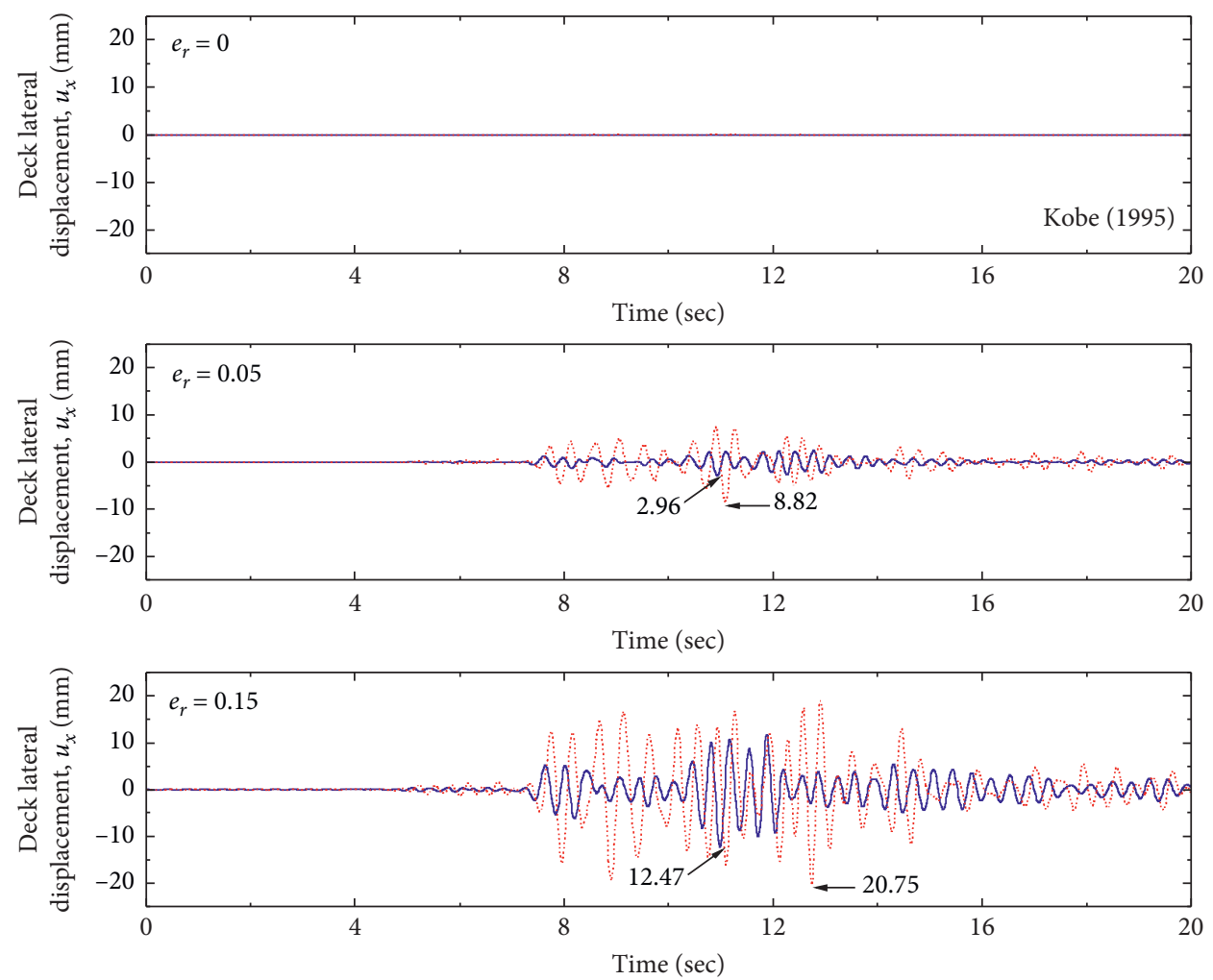

Without SSI
W.... With SSI $\left(v_{s}=150 \mathrm{~m} / \mathrm{s}\right)$

FIGURE 16: Displacement time-history response of torsionally uncoupled and coupled nonisolated framed-type machine foundation under the Kobe, 1995 earthquake. 
TABle 4: Peak deck acceleration and displacement obtained from the FE analysis of base-isolated machine foundation.

\begin{tabular}{|c|c|c|c|c|c|}
\hline \multirow{2}{*}{ Case } & & \multicolumn{2}{|c|}{ Peak deck acceleration, $\ddot{u}_{y g}(g)$} & \multicolumn{2}{|c|}{ Peak deck displacement, $u_{y}(\mathrm{~mm})$} \\
\hline & & Without SSI & With SSI & Without SSI & With SSI \\
\hline \multicolumn{6}{|c|}{ Imperial Valley, array \#5, 1979} \\
\hline Torsionally uncoupled & & 0.47 & 0.37 & 14.16 & 28.93 \\
\hline \multirow{2}{*}{ Torsionally coupled } & $e_{r}=0.05$ & 0.49 & 0.96 & 16.15 & 28.69 \\
\hline & $e_{r}=0.15$ & 0.52 & 0.97 & 21.01 & 27.60 \\
\hline \multicolumn{6}{|l|}{ Northridge, 1994} \\
\hline Torsionally uncoupled & & 0.66 & 1.73 & 19.92 & 49.73 \\
\hline \multirow{2}{*}{ Torsionally coupled } & $e_{\mathrm{r}}=0.05$ & 0.70 & 1.73 & 22.85 & 49.08 \\
\hline & $e_{\mathrm{r}}=0.15$ & 0.72 & 1.74 & 27.83 & 47.47 \\
\hline \multicolumn{6}{|l|}{ Kobe, 1995} \\
\hline Torsionally uncoupled & & 0.25 & 1.66 & 7.62 & 61.43 \\
\hline \multirow{2}{*}{ Torsionally coupled } & $e_{\mathrm{r}}=0.05$ & 0.25 & 1.66 & 8.13 & 61.58 \\
\hline & $e_{\mathrm{r}}=0.15$ & 0.24 & 1.65 & 9.26 & 61.86 \\
\hline
\end{tabular}
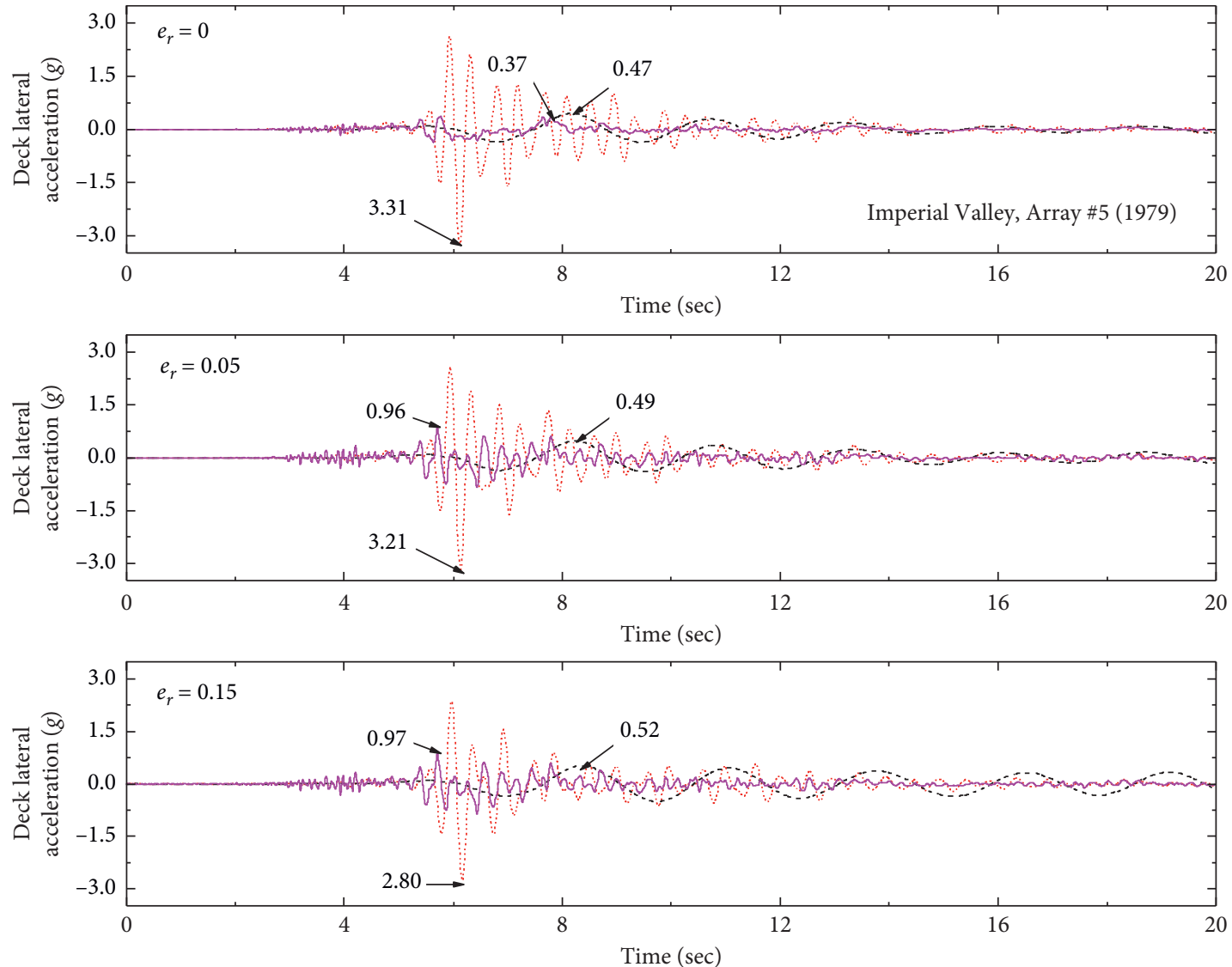

$\begin{array}{ll}\text { …. } & \text { Nonisolated (with SSI) } \\ \text { - - - Base-isolated (without SSI) } \\ \text { — Base-isolated (with SSI) }\end{array}$

FIGURE 17: Acceleration time-history response of torsionally uncoupled and coupled base-isolated framed-type machine foundation under the Imperial Valley, Array \# 5, 1979 earthquake.

machine, the amplitude of vibration also needs to be within the prescribed permissible limits. Otherwise, the design becomes unacceptable. Therefore, to limit the response of machine foundation within the permissible limits, it is essential to understand the different parameters affecting the response of machine foundation against earthquake ground motion.
In general, the superstructure frequency ratio, $\lambda_{s}$ (the ratio between the uncoupled torsional frequency to the uncoupled lateral frequency) for the framed structures will be in the range of 0.5 to 1.5 . For the present study, the superstructure frequency ratio of the typical TG foundation considered is $\lambda_{\mathrm{s}}=1.37$ (i.e. torsional frequency of $4.48 \mathrm{~Hz}$ 

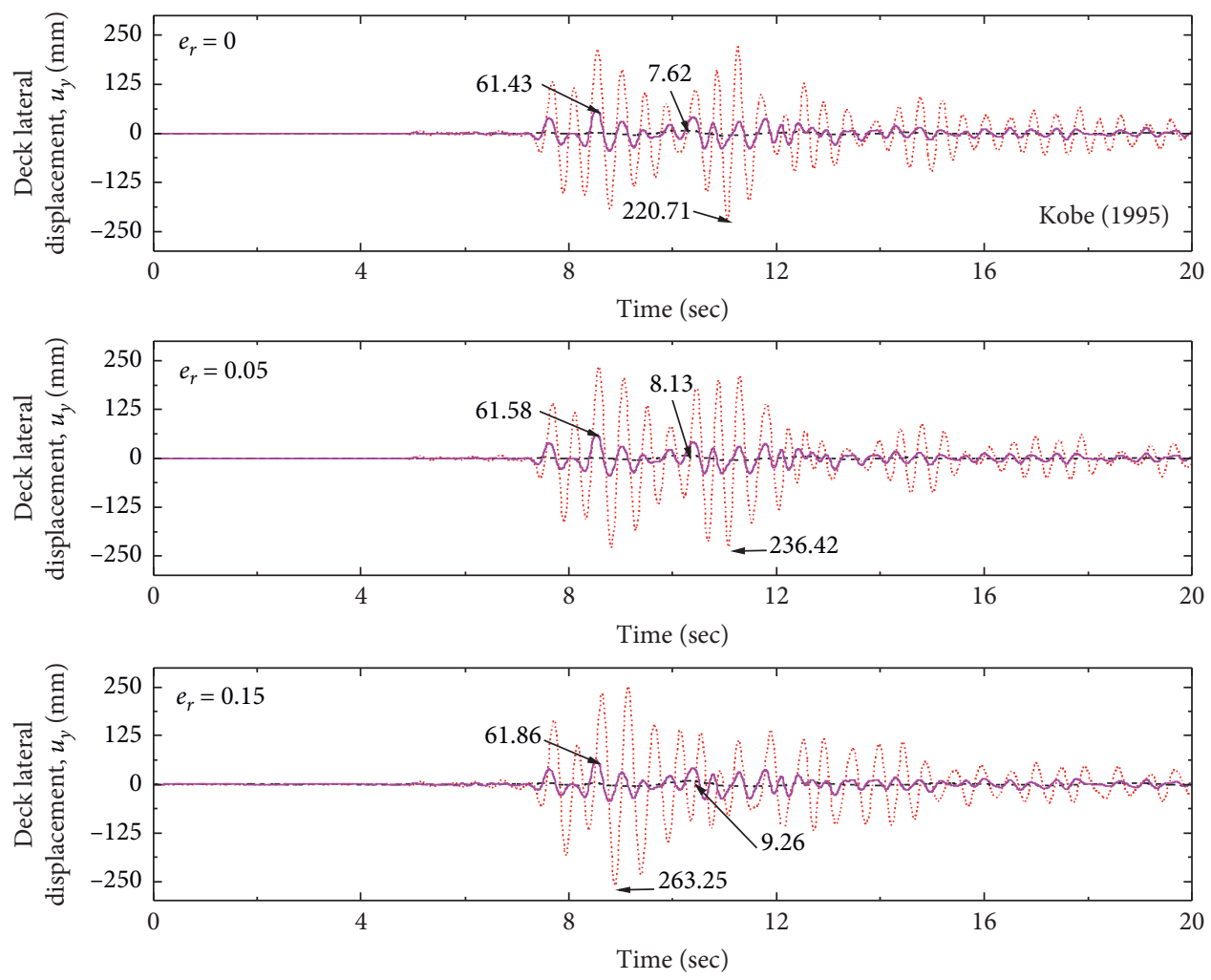

$\begin{array}{ll}\text {..... } & \text { Nonisolated (with SSI) } \\ \text { - - - } & \text { Base-isolated (without SSI) } \\ \text { - } & \text { Base-isolated (with SSI) }\end{array}$

FIGURE 18: Displacement time-history response of torsionally uncoupled and coupled base-isolated framed-type machine foundation under the Kobe, 1995, earthquake.

and lateral frequency of $3.26 \mathrm{~Hz}$ as given in Table 1). Two different eccentricity ratios, $e_{\mathrm{r}}=0.05$ and 0.15 , are considered including the accidental eccentricity of 0.05 as specified by the UBC [43] to compare the effect of torsional coupling, and the results are compared with the torsionally uncoupled system $\left(e_{\mathrm{r}}=0\right)$.

4.1. Effect of Torsional Coupling on Natural Frequency. In order to study the effect of torsional coupling on natural frequencies, TG foundations of different frequencies (by assuming different machine masses) are considered with different eccentricity ratios $\left(e_{r}\right)$. The total mass of the machine (machine mass and deck masses) is varied such that the superstructure frequency ratio comes in the range of 1.40 , which is typically adopted in practice while designing the TG foundation. The variations in natural frequencies in the first mode $\left(\omega_{n 1}\right)$ and the second mode $\left(\omega_{n 2}\right)$ are shown in Figure 7(a). It is observed from Figure 7(a) that there is a significant reduction in coupled natural frequencies in fundamental mode when the eccentricity ratio is high, especially when the structural time period of TG foundation is low, i.e., for the rigid superstructure. Also, the natural frequencies in lateral and torsional modes are closer for the rigid TG foundation. The variation in natural frequency ratios in the first mode $\left(\lambda_{n 1}\right)$ and the second mode $\left(\lambda_{n 2}\right)$ are shown in Figure 7(b). It is noticed from the Figure 7(b) that when the frequency ratio is close to one, i.e., for torsionally tuned structural arrangement, the coupled natural frequencies in translational and torsional modes are quite close even with the code-specified accidental eccentricity $\left(e_{r}=0.05\right)$ as observed by past studies [25]. In such cases, the modal coupling amplifies the dynamic response, which is critical in machine foundations. The natural frequencies obtained from the FE analysis for the TG foundation considered in the study are summarized in Table 1. It is evident from the results that the presence of superstructure eccentricities alters the natural frequencies significantly. It is well-known that the fundamental natural frequency is the most important parameter in the design of machine foundations. Hence, ignoring the superstructure eccentricities could lead to unsafe design.

4.2. Effect of SSI on Natural Frequency. The natural frequencies of the TG foundation duly considering the SSI obtained from the FE analysis are presented in Table 1. It is inferred from the results that the effects of SSI decrease the natural frequency of the TG foundation, which is significant even in higher modes. The reduction in natural frequencies due to SSI effects is in the range of $20 \%$ to $30 \%$. Hence, the 

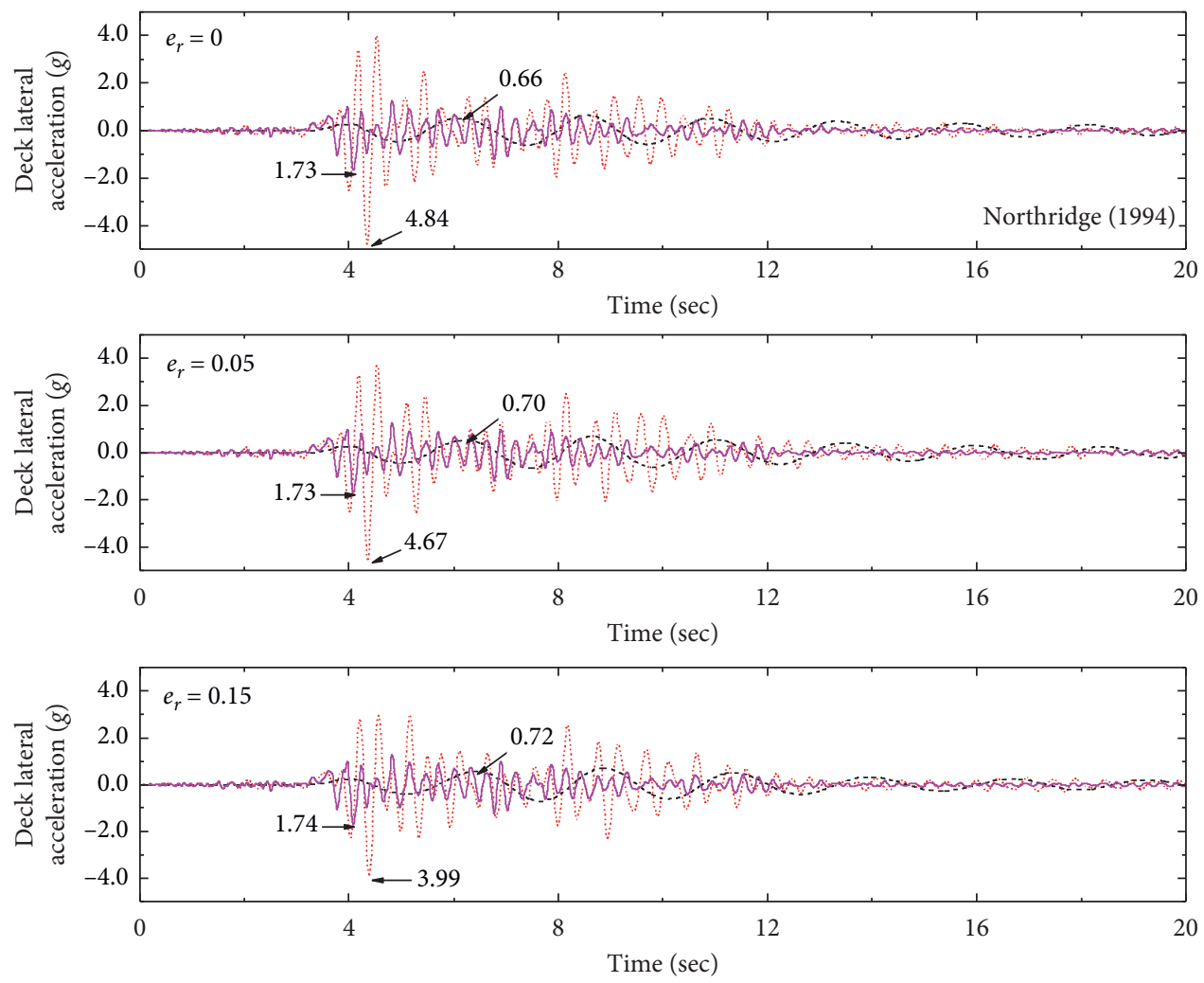

.... Nonisolated (with SSI)

--- Base-isolated (without SSI)

- Base-isolated (with SSI)

FIGURE 19: Acceleration time-history response of torsionally uncoupled and coupled base-isolated framed-type machine foundation under the Northridge, 1994 earthquake.

SSI activates the higher mode participation, resulting in an amplified response. It is also evident from the results ( $\mathrm{Ta}-$ ble 1) that the presence of superstructure eccentricities further reduces the natural frequencies.

\subsection{Effect of SSI on Torsionally Coupled TG Foundation.} To estimate the SSI effects on torsionally coupled TG foundation under earthquake ground motions, the dynamic response parameters such as deck accelerations and displacements are obtained from the FE analysis. Three different earthquake ground motions are considered in the present study (Table 2). The dynamic response obtained for two different eccentricity ratios $\left(e_{r}=0.05\right.$ and 0.15$)$ along with the torsionally uncoupled condition are summarized in Table 3. From the results, it is inferred that the deck accelerations and lateral displacements increase with an increase in eccentricity ratio. The SSI effects further amplify the dynamic response. The time-history response of deck acceleration and displacement for the torsionally coupled TG foundation under the chosen earthquakes is shown in Figures 8-16, respectively. Figure 8 shows the time variation of deck acceleration of $\mathrm{TG}$ foundation under Imperial Valley, 1979 (Array \# 5) earthquake ground motion with and without considering the SSI (i.e., fixed-base condition). The responses of torsionally coupled and uncoupled conditions are also compared in the same figure. It is observed from Figure 8 that the deck accelerations increase with an increase in eccentricity ratio. The effects of SSI amplify the dynamic responses significantly. A similar trend of response is observed in the case of the 1994 Northridge and 1995 Kobe earthquake motion, as shown in Figures 9 and 10. Figure 11 shows the time variation of deck displacement in $y$-direction under Imperial Valley, 1979 (Array \# 5) earthquake ground motion. It is observed from the figure that the deck displacement in $y$-directions increases with an increase in eccentricity ratio. In addition, the SSI effects amplify the deck displacement similar to acceleration.

A similar response is observed for the other two earthquake motions, as shown in Figures 12 and 13. Figure 14 shows the time variation of deck displacement in the $x$-direction (due to excitation in torsional modes because of the asymmetries involved) under Imperial Valley, 1979 (Array \# 5) earthquake ground motion. It is observed from the figure that the deck displacement in $x$-directions also increases with an increase in eccentricity ratio and SSI. A similar trend of deck displacement in the $x$-direction is observed for the other two earthquake motions as shown in Figures 15 and 16. Therefore, it is concluded that neglecting the superstructure eccentricity in the TG foundation would 

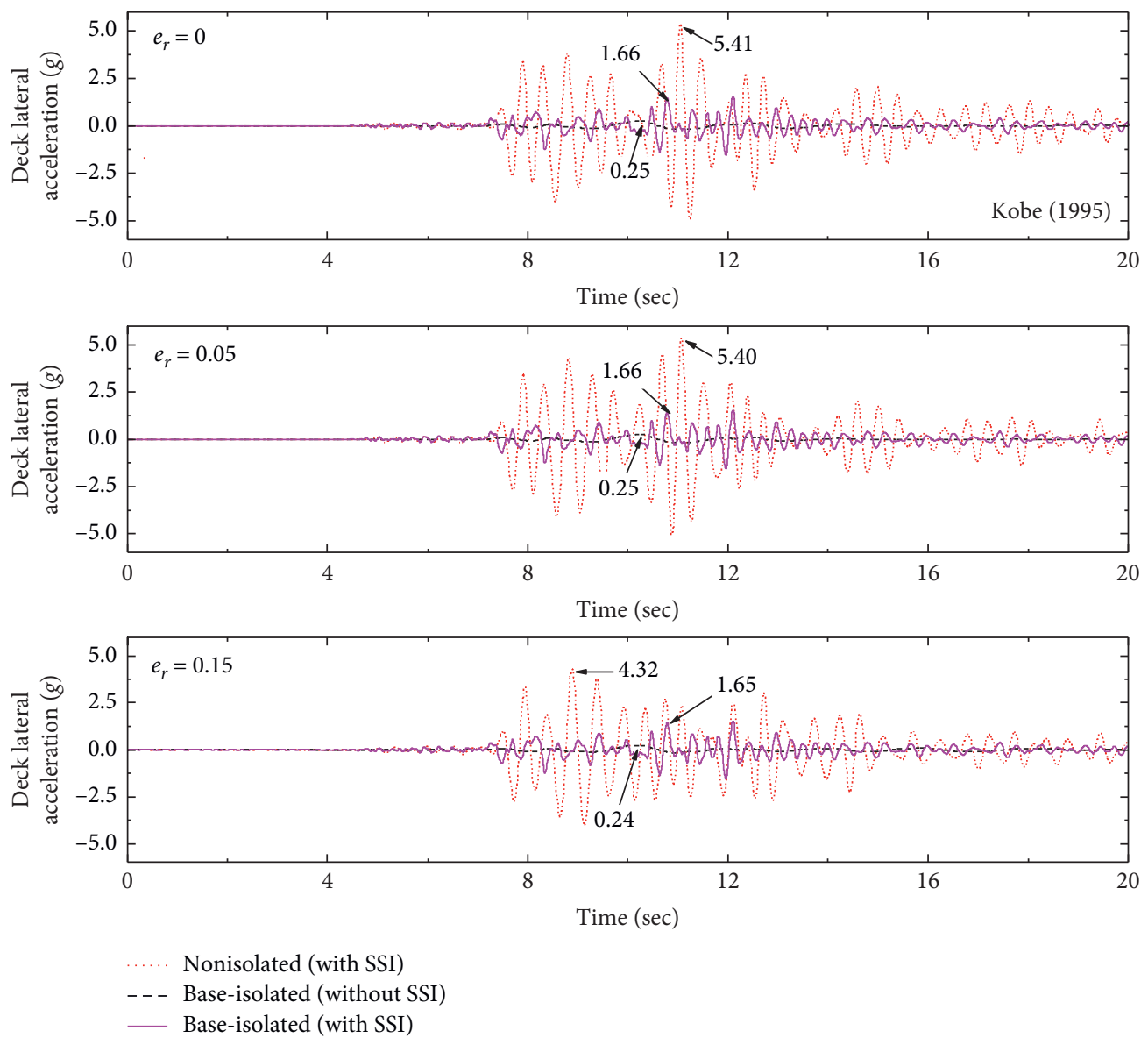

FIGURE 20: Acceleration time-history response of torsionally uncoupled and coupled base-isolated framed-type machine foundation under the Kobe, 1995, earthquake.

underestimate the dynamic response. Also, the effects of SSI activate the higher mode participation, resulting in amplified response: acceleration and displacement at deck level in the TG foundation. Hence, ignoring the effects of SSI would also lead to inadequate design.

4.4. Effect of SSI on Torsionally Coupled Base-Isolated Foundation. In the present study, the beneficial effects of base isolators in machine foundations under the influence of torsional coupling are studied. Also, the SSI effects in baseisolated machine foundations are also investigated. The LRB type base isolator is considered for the present study and the input parameters considered are isolator time period, $T_{\mathrm{b}}=2.5 \mathrm{sec}$, isolator damping, $\xi_{\mathrm{b}}=0.05$, and yield displacement, $q=2.5 \mathrm{~cm}$. The dynamic responses are obtained for two different eccentricity ratios $\left(e_{\mathrm{r}}=0.05\right.$ and 0.15$)$ along with the torsionally uncoupled condition and the results are summarized in Table 4. The typical time-history response of deck acceleration and displacement is shown in Figures 17 and 18. Figure 17 shows the time variation of deck acceleration of TG foundation isolated by the LRB system under Imperial Valley, 1979 (Array \# 5) earthquake ground motion. It is observed from the figure that the deck acceleration in the base-isolated machine foundation is significantly reduced as compared to the nonisolated machine foundation. In addition, it is also inferred that the effect of torsional coupling in the superstructure is insignificant on the performance of base-isolated TG foundation when SSI is neglected. However, the deck acceleration is amplified significantly when the effect of SSI is considered; the amplification further increases if the effect of torsional coupling is combined with SSI for base-isolated machine foundation.

Similar behavior is observed for the other earthquakes (1994 Northridge and 1995 Kobe earthquake motion) as shown in Figures 19 and 20 . Figure 21 shows the time variation of deck displacement in $y$-direction under Imperial Valley, 1979 (Array \# 5) earthquake ground motion. It is observed from the figure that the deck displacement in the base-isolated machine foundation is significantly reduced as compared to the nonisolated machine foundation. A similar reduction in deck displacement is also noticed for the other 

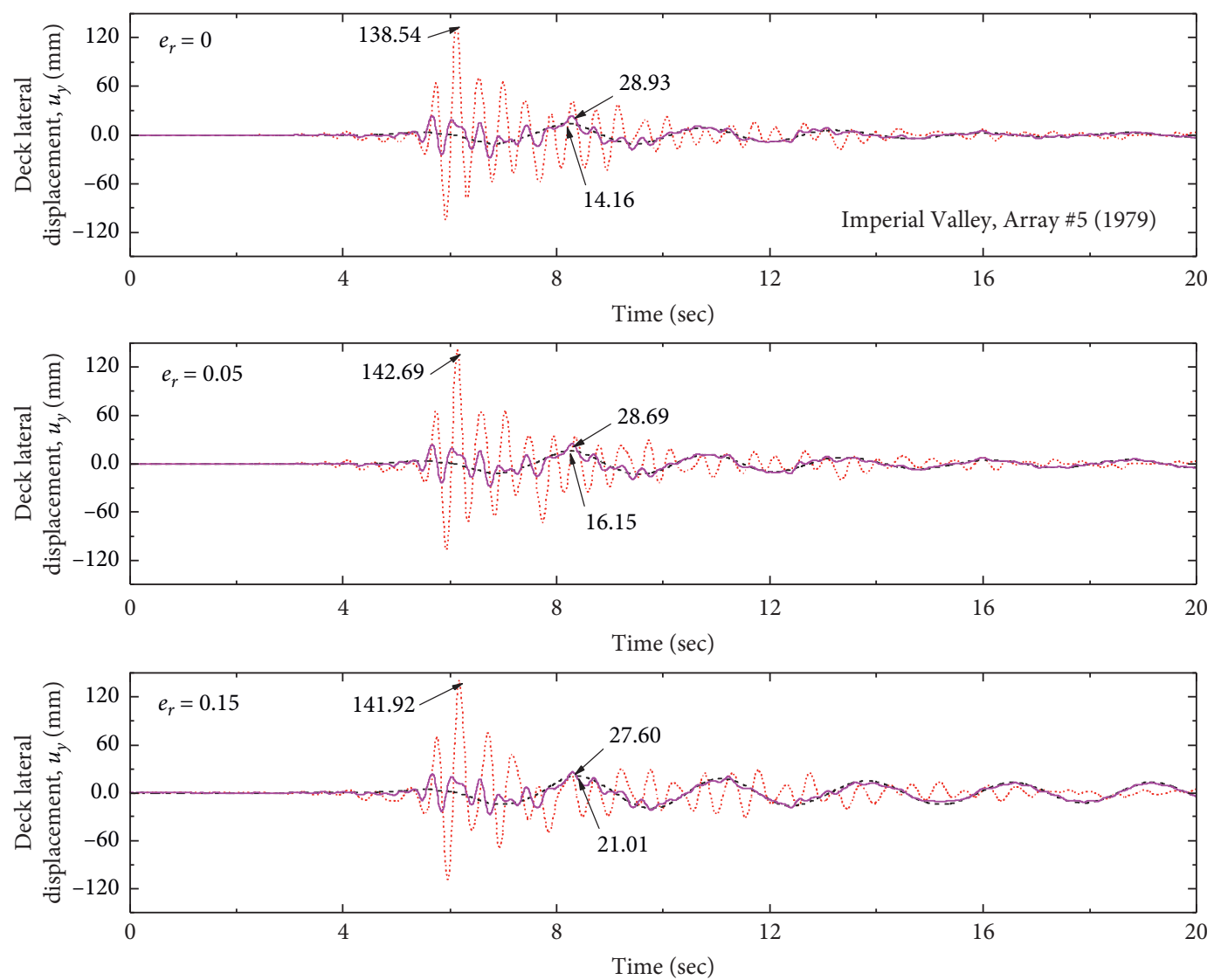

$\begin{array}{ll}\ldots \ldots . & \text { Nonisolated (with SSI) } \\ \text { - - - } & \text { Base-isolated (without SSI) } \\ \text { _ Base-isolated (with SSI) }\end{array}$

Figure 21: Displacement time-history response of torsionally uncoupled and coupled base-isolated framed-type machine foundation under the Imperial Valley, Array \# 5, 1979, earthquake.

two earthquake motions as shown in Figures 18 and 22. However, the percentage reduction is found to be different. Hence, it is concluded that the combined effects of torsional coupling in the superstructure and the SSI need to be considered in the design of the base-isolated TG foundation.

\section{Summary and Conclusions}

$\mathrm{FE}$ analysis is carried out to evaluate the dynamic response of a typical base-isolated TG foundation subjected to different earthquake ground motions. The effects of torsional coupling in machine foundation are also studied and the results are compared with the torsionally uncoupled case. Soft soil conditions are considered to analyze the effects of SSI and the results are compared with the fixed-base condition. From the results of the present study, the following conclusions are drawn:

(1) The SSI effects decrease the natural frequency of the entire structure-foundation-soil system, which is significant in higher modes, especially for TG foundation resting on soft soil strata. Also, the dynamic response of such machine foundations is greatly affected by the presence of superstructure eccentricities. The natural frequencies in lower modes are further reduced by the superstructure eccentricities.

(2) The SSI effects increase the deck acceleration and lateral displacement in TG foundation resting on soft soil strata. In addition, the deck acceleration and lateral displacement are also increased in such machine foundations when the superstructure eccentricities are considered. Due to the excitation in torsional modes, the horizontal displacement in the other direction is also increased significantly with an increase in eccentricity ratio.

(3) Since the TG foundations are rigid as compared to the conventional low-rise buildings, the forces exerted on the superstructure are severe under earthquake ground motions. Hence, the base isolators are beneficial in TG foundations, by which the superstructure accelerations are greatly reduced. In addition, the relative deck displacements are also greatly reduced with the help of base isolators. Hence, base isolators are beneficial to protect sensitive equipment from damaging earthquake events. 

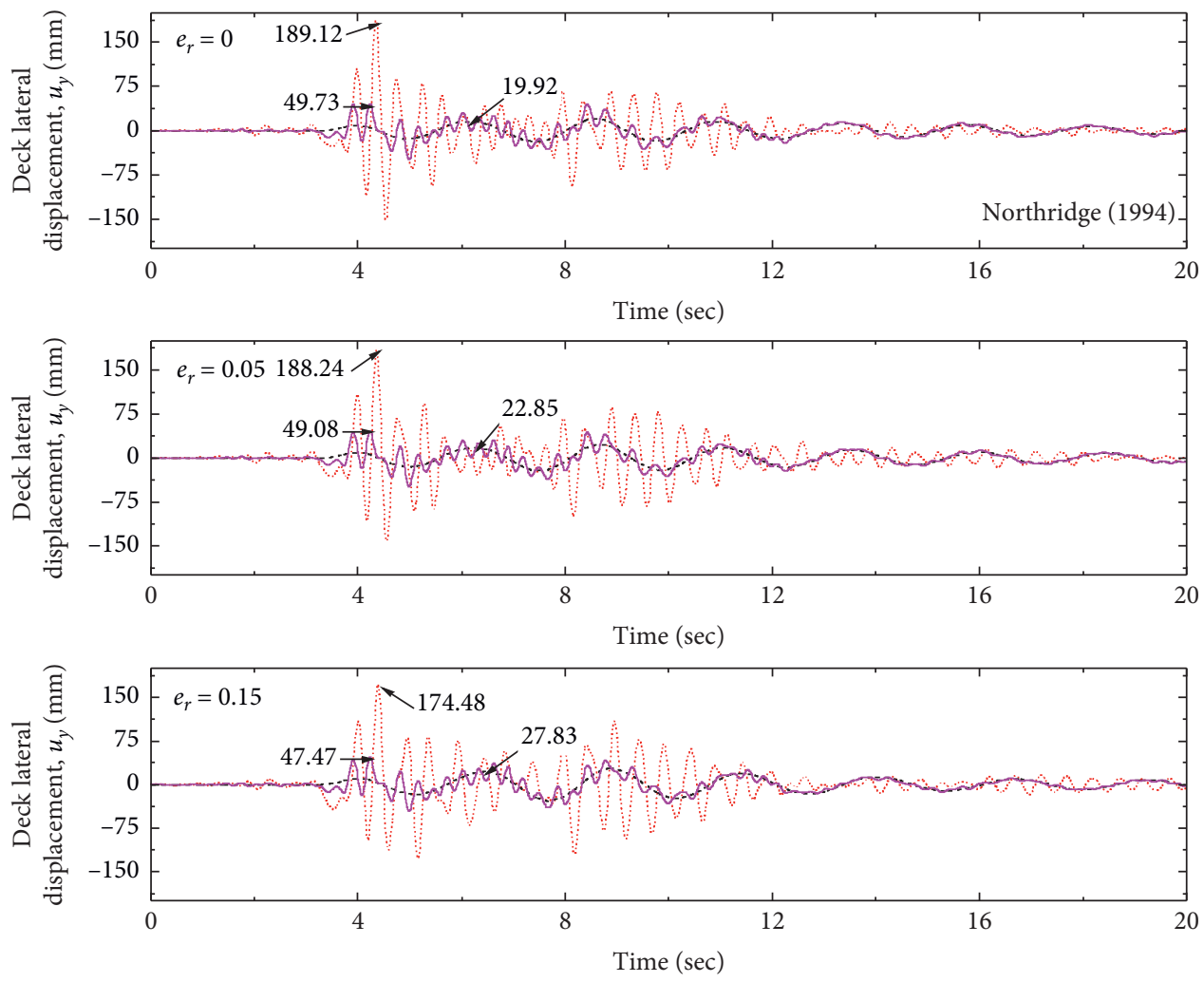

$\begin{array}{ll}\ldots \ldots . & \text { Nonisolated (with SSI) } \\ \text { - - - } & \text { Base-isolated (without SSI) } \\ \text { _ } & \text { Base-isolated (with SSI) }\end{array}$

Figure 22: Displacement time-history response of torsionally uncoupled and coupled base-isolated framed-type machine foundation under the Northridge, 1994, earthquake.

(4) Though the deck accelerations are significantly reduced by using the base isolators, in the case of the soft soil, the involvement of higher mode participation amplifies the seismic response. The amplification is found to increase further when the effects of torsional coupling and SSI are combined. Hence, neglecting the effects of SSI and torsional coupling in the dynamic response of base-isolated TG foundations may lead to poor performance of machine foundations.

5.1. Limitations. In this research, the effects of soil-structure interaction on the dynamic response of machine foundations are investigated by considering elastic soil parameters. However, it would be interesting to study the dynamic response by considering nonlinear soil behavior, especially under earthquake ground motions.

\section{Data Availability}

Some or all data, models, or codes that support the findings of this study are available from the corresponding author upon reasonable request.

\section{Conflicts of Interest}

The authors declare that they have no conflicts of interest.

\section{References}

[1] BIS (Bureau of Indian Standards), IS 2974 (Part III)-Design and Construction of Machine Foundations - Code of Practice, Foundations for Rotary Type Machines (Medium and High Frequency) Second Revision, Bureau of Indian Standards, New Delhi, India, 1992.

[2] P. Srinivasulu and V. Vaidyanathan, Handbook of Machine Foundations, Tata McGraw-Hill Publishing Company, New Delhi, India, 1980.

[3] ACI (American Concrete Institute), ACI 351.3R-04, Foundations for Dynamic Equipment, Farmington Hills, MI, USA, 2004.

[4] G. Gazetas, "Analysis of machine foundation vibrations: stateof-the-art," Soil Dynamics and Earthquake Engineering, vol. 2, pp. 1-42, 1983.

[5] J. P. Wolf, "Spring-dashpot-mass models for foundation vibrations," Earthquake Engineering \& Structural Dynamics, vol. 26, no. 9, pp. 931-949, 1997.

[6] S. F. Jan and S. C. Wu, Dynamic Analysis and Design of Large Compressor Foundations in High Seismic Zone, Structures Congress, pp. 2702-2713, ASCE, Kingston, Australia, 2010.

[7] A. Petrash, W. Bounds, and S. Wong, Designing Foundations for Vibrating Machinery: Dealing with Soil \& Software Issues, Structures Congress, pp. 2443-2457, ASCE, Kingston, Australia, 2011.

[8] Z. Liu, Design of Foundations for Large Dynamic Equipment in a High Seismic Region, pp. 1403-1414, ASCE, Kingston, Australia, 2013. 
[9] S. Biswas and B. Manna, "Experimental and theoretical studies on the nonlinear characteristics of soil-pile systems under coupled vibrations," Journal of Geotechnical and Geoenvironmental Engineering, vol. 144, no. 3, 2018.

[10] O. S. Ali and M. Mahamid, "Effect of soil-foundation interaction on the dynamic response of a four-cylinder compressor foundation," Practice Periodical on Structural Design and Construction, 2018.

[11] J. Bose, J. S. Saini, H. Liu, T. Elkhoraibi, and F. Ostadan, $A$ Case Study on the Dynamic Analysis of a Combustion Turbine Generator Foundation Using Different Soil Modeling Approaches, pp. 432-443, ASCE, Kingston, Australia, 2018.

[12] J. M. Kelly, "Aseismic base isolation: review and bibliography," Soil Dynamics and Earthquake Engineering, vol. 5, no. 4, pp. 202-216, 1986.

[13] R. S. Jangid and T. K. Datta, "The stochastic response of asymmetric base isolated buildings," Journal of Sound and Vibration, vol. 179, no. 3, pp. 463-473, 1995.

[14] V. A. Matsagar and R. S. Jangid, "Impact response of torsionally coupled base-isolated structures," Journal of Vibration and Control, vol. 16, no. 11, pp. 1623-1649, 2010.

[15] X. X. Bai, N. M. Wereley, and D. H. Wang, "Control and analysis of a magnetorheological energy absorber for both shock and vibration," International Journal of Acoustics and Vibration, vol. 22, pp. 104-110, 2017.

[16] R. N. Jabary and G. S. P. Madabhushi, "Structure-soilstructure interaction effects on structures retrofitted with tuned mass dampers," Soil Dynamics and Earthquake Engineering, vol. 115, pp. 90-103, 2017.

[17] International Code Council, IBC (International Building Code), International Code Council, Country Club Hills, IL, USA, 2009.

[18] AASHTO (American Association of State Highway and Transportation Officials), Guide Specifications for Seismic Isolation Design, AASHTO (American Association of State Highway and Transportation Officials, Washington, D.C., USA, 2010.

[19] W.-C. Su, A. G. Hernried, and S. C. S. Yim, "Seismic response of rotating machines-structure-RFBI systems," Earthquake Engineering \& Structural Dynamics, vol. 29, no. 2, pp. 213240, 2000 .

[20] V. A. Ivovich and M. K. Savovich, "Isolation of floor machines by lever-type inertial vibration corrector," Proceedings of the Institution of Civil Engineers - Structures and Buildings, vol. 146, no. 4, pp. 391-402, 2001.

[21] A. G. Chehab and M. H. El Naggar, "Design of efficient base isolation for hammers and presses," Soil Dynamics and Earthquake Engineering, vol. 23, no. 2, pp. 127-141, 2003.

[22] R. A. Ibrahim, "Recent advances in nonlinear passive vibration isolators," Journal of Sound and Vibration, vol. 314, no. 3-5, pp. 371-452, 2008.

[23] International Code Council, IBC (International Building Code), International Code Council, Falls Church, VA, USA, 2009.

[24] R. Danisch and M. Labes, "Aseismic design of turbine houses for nuclear power plants," Nuclear Engineering and Design, vol. 38, no. 3, pp. 495-501, 1976.

[25] A. M. Chandler and G. L. Hutchinson, "Torsional coupling effects in the earthquake response of asymmetric buildings," Engineering Structures, vol. 8, no. 4, pp. 222-236, 1986.

[26] H. Sikaroudi and A. M. Chandler, "Structure-foundation interaction in the earthquake response of torsionally asymmetric buildings," Soil Dynamics and Earthquake Engineering, vol. 11, no. 1, pp. 1-16, 1992.
[27] H. Shakib and A. Fuladgar, "Dynamic soil-structure interaction effects on the seismic response of asymmetric buildings," Soil Dynamics and Earthquake Engineering, vol. 24, no. 5 , pp. $379-388,2004$

[28] M. Eisenberger and A. Rutenberg, "Seismic base isolation of asymmetric shear buildings," Engineering Structures, vol. 8, pp. 2-8, 1985.

[29] R. S. Jangid and J. M. Kelly, "Torsional displacements in baseisolated buildings," Earthquake Spectra, vol. 16, no. 2, pp. 443-454, 2000.

[30] V. A. Matsagar and R. S. Jangid, "Base-isolated building with asymmetries due to the isolator parameters," Advances in Structural Engineering, vol. 8, pp. 1-19, 2005.

[31] M. C. Constantinou, "A simplified analysis procedure for base-isolated structures on flexible foundation," Earthquake Engineering \& Structural Dynamics, vol. 15, no. 8, pp. 963983, 1987.

[32] C. C. Spyrakos, C. A. Maniatakis, and I. A. Koutromanos, "Soil-structure interaction effects on base-isolated buildings founded on soil stratum," Engineering Structures, vol. 31, no. 3, pp. 729-737, 2009.

[33] Z. Haiyang, Y. Xu, Z. Chao, and J. Dandan, "Shaking table tests for the seismic response of a base-isolated structure with the SSI effect," Soil Dynamics and Earthquake Engineering, vol. 67, pp. 208-218, 2014.

[34] B. G. Look, Handbook of Geotechnical Investigation and Design Tables, Taylor \& Francis Group, London, UK, 2007.

[35] K. J. Bentley and M. H. E. Naggar, "Numerical analysis of kinematic response of single piles," Canadian Geotechnical Journal, vol. 37, no. 6, pp. 1368-1382, 2000.

[36] B. K. Maheshwari, K. Z. Truman, M. H. E. Naggar, and P. L. Gould, "Three-dimensional finite element nonlinear dynamic analysis of pile groups for lateral transient and seismic excitations," Canadian Geotechnical Journal, vol. 41, no. 1, pp. 118-133, 2004.

[37] M. Novak and H. Mitwally, "Transmitting boundary for axisymmetrical dilation problems," Journal of Engineering Mechanics, vol. 114, no. 1, pp. 181-187, 1988.

[38] O. C. Zienkiewicz, C. Emson, and P. Bettess, "A novel boundary infinite element," International Journal for $\mathrm{Nu}$ merical Methods in Engineering, vol. 19, no. 3, pp. 393-404, 1983.

[39] J. Lysmer and R. L. Kuhlemeyer, "Finite dynamic model for infinite media," Journal of the Engineering Mechanics Division, vol. 95, no. 4, pp. 859-877, 1969.

[40] C. Zhao and S. Valliappan, "A dynamic infinite element for three-dimensional infinite-domain wave problems," International Journal for Numerical Methods in Engineering, vol. 36, no. 15, pp. 2567-2580, 1993.

[41] T. P. Peiris, D. P. Thambiratnam, N. J. Perera, and C. Gallage, "An insight into kinematic interaction of pile embedded in deep layered marine sediment under seismic excitation," International Journal of Recent Research and Applied Studies, vol. 16, pp. 360-369, 2013.

[42] K. Fan, G. Gazetas, A. Kaynia, E. Kausel, and S. Ahmad, "Kinematic seismic response of single piles and pile groups," Journal of Geotechnical Engineering, vol. 117, no. 12, pp. 1860-1879, 1991.

[43] International Conference of Building Official, UBC (Uniform Building Code), International Conference of Building Official, Whittier, CA, USA, 1997. 